\title{
Social Interaction Processes and Personality
}

\author{
Mitja D. Back \\ University of Münster, Germany
}

Chapter, in press

To appear in:

J. Rauthmann (Ed.), The handbook of personality dynamics and processes. Elsevier.

This is an unedited manuscript accepted for publication. The manuscript will undergo copyediting, typesetting, and review of resulting proof before it is published in its final form

\begin{abstract}
Author Note
Correspondence concerning this article should be addressed to Mitja Back, Department of Psychology, University of Münster, Fliednerstr. 21, 48149 Münster, Germany. Email: mitja.back@wwu.de
\end{abstract}




\begin{abstract}
Social interactions are one of the most relevant contexts of our lives and they are intimately connected to the conceptualization, dynamics, development, and consequences of personality. In this chapter, I will first analyze the way social interactions unfold via interaction states of all interaction partners and describe how people differ in social interaction processes. Following the PERSOC model, I will argue that these individual differences are a key window to understanding the nature of some of the most popular personality traits (e.g., extraversion, dominance, shyness, agreeableness, narcissism), as well as their effects on and development in social relationships. Empirical research on individual differences in interaction state levels, contingencies, and fluctuations is summarized. In closing, I describe a couple of current limitations, and outline perspectives for understanding and assessing personality traits as dynamic social interaction systems.
\end{abstract}

Keywords: social interaction, relationships, interpersonal perception, behavioral expression, contingencies, personality processes 
Talking to a good friend, playing with your child, discussing a project in a work group, having a party, giving a talk, fighting with your neighbor, negotiating a division of labor with your roommate, planning a vacation with your partner, introducing yourself to a new group of peers, kissing someone and having sex, chatting with a salesperson, having lunch with your colleagues, skyping with a collaborator, realizing a relaxing evening with your partner, trying to impress someone, discussing a reoccurring conflict theme with your mother, flirting with a stranger in a bar, winning and losing a game with your sports team, asking your boss for advice, having dinner with your family: Interacting with others is arguably one of the most prevalent and important contexts of our lives. Few human beings would be able to describe their lives and derive meaning without engaging in and/or referring to one or more of the interactive situations mentioned above. We, as humans, strive for social achievements (getting ahead) and social belongingness (getting along; Bakan, 1966; Baumeister \& Leary, 1995; Hogan, 1983; Pittman \& Zeigler, 2007) - goals that are difficult to meet without some sort of social interaction.

In this chapter, I will analyze the way these social interactions unfold via interaction states of all interaction partners and how people differ therein. I will also argue that understanding individual differences in social interaction processes is key to understanding the nature of some of the most popular personality traits (e.g., extraversion, dominance, shyness, agreeableness, narcissism), as well as their effects on and development in social relationships. This way, research on social interaction processes can help to gain a more dynamic, process-oriented view on personality.

To ease understanding, I will first briefly define some of the basic terms I will use. I define "social interactions" as situations with a circumscribable setting, onset, and ending in which two or more people are aware of and psychologically react to one another (Back, Baumert et al., 2011). With "interaction states", I refer to these psychological reactions that take place in the moment and during an interaction. These interaction states can be 
experiential in nature and, therefore, not directly observable (e.g., affective and perceptual states) or behavioral and, therefore, directly observable. "Interaction processes" refer to changes in interaction states and can be describes as either the realization of certain state levels (i.e., how much a perception, an affect is experienced or a behavior is expressed) or as contingencies between one interaction state and another (i.e., how much variation in one state realization affects variation in another state realization). ${ }^{1}$

While states are happening in the moment (i.e., in a given context and at a given point in time), "traits" describe individuals' typical functioning across time. In this sense, interpersonal traits are, thus, simply abstractions of interindividual differences in interaction states: The way individuals typically perceive, think, feel, desire, and behave during social interactions as compared with others. I do not restrict the term "trait" to specific content domains or a specific level of aggregation but regard any experiential and/or behavioral regularity (i.e., with at least some stability across time) that varies across persons as a trait. A trait can be broader or more specific depending on how many state differences in how many contexts it subsumes. In a very similar sense, social relationships can be defined by the typical functioning of dyads or groups across time. Social relationships, thus, reflect stable differences between dyads or groups in interaction states. For example, the way two individuals typically perceive and think about each other, feel in the presence of the other, and behave towards each other as compared to their interaction traits with other individuals.

\section{Situating Social Interaction Processes:}

\section{Structure and Content of a Complex Process Domain of Personality}

Following the general behavior-/self-regulatory cycle (Carver \& Scheier, 1981; Heckhausen, 1991) and self-regulatory perspectives on personality (Denissen, Wood, Penke, \& van Aken, 2013; Hennecke, Bleidorn, Denissen, \& Wood, 2014; Morf, 2006; Wood \& Denissen, 2015), personality processes can be sorted to belonging to either a pre-action, action, or post-action phase (see Geukes, van Zalk, \& Back, 2017, 2018). In this Chapter, I 
will focus on personality processes that take place during social interactions, that is, in the action phase. Thus, I will neither summarize and discuss research on interpersonal processes that refer to social preferences, expectations, situation selections, goals, and strategies that take place before entering a social interaction (pre-action phase) nor interpersonal processes that refer to the evaluation, attribution, and narration of social interaction outcomes (postaction phase). These non-interactional interpersonal processes are, of course, highly relevant as well, and they can be systematically combined with interaction processes for a comprehensive conceptualization of interpersonal aspects of personality (see Figure 1; see Geukes et al., 2018 for details).

- Fig. 1 here -

Social interaction processes are in a way special and particularly complex and interesting because they do not only take place within the mental system of only one individual but, instead, pertain to the ways in which the mental systems of two or more individuals affect each other - via observable interaction behaviors. As outlined in lens model approaches (Brunswik, 1956; Karelaia, \& Hogarth, 2008), humans try to make sense of their environment by focusing on subsets of observable cues to infer not directly observable environmental features. Applied to the context of social interaction and personality processes (Back \& Nestler, 2016; Back, Schmukle, \& Egloff, 2011; Hall, Gunnery, Letzring, Carney, \& Colvin, 2017; Hirschmüller, Egloff, Nestler, Back, 2013; Nestler \& Back, 2013; Nestler, Egloff, Küfner, \& Back, 2012; Stopfer, Nestler, Egloff, \& Back, 2014): Humans try to make sense of their interaction partner by focusing on subsets of the interaction partner's behaviors to infer the current mental states and stable traits of their interaction partners. The resulting judgments are then mentally processed leading to all sorts of self-related cognitions, metaperceptions and affective reactions based on which own actions are triggered (Back, Baumert et al., 2011; Hopwood, 2018; Pincus, Hopwood, \& Wright, in press; Rauthmann, 2016). 
These complexities need to be considered when conceptualizing interaction state process pathways and trying to assess relevant data.

Another related way of approaching social interactions from a personality perspective is to conceptualize the interaction partner(s) as situations and regard social interactions as a special case of person-situation transactions (Asendorpf, in press; Malloy \& Kenny, 1986). In social interactions, the interaction partner is the most powerful aspect of the situation providing the most salient and relevant environmental cues, and being most clearly affected by one's own actions. In the same way person-situation transaction research more generally distinguishes person, situation, and person-situation interaction components of social behavior (e.g., Endler \& Hunt, 1966; Krueger, 2009; Snyder \& Ickes, 1985), the observed variability in social interaction states can be decomposed into actor components (individual differences in how one acts, feels, and perceives others in general in social interactions), partner components (individual differences in how one evokes behaviors and feelings and is perceived by others in general in social interactions), and relationship components (dyadic differences in the unique behaviors, feelings, and perceptions towards and from a specific other individual). When it comes to predicting these variance components by actor, partner, and relationship characteristics, social interaction research offers one crucial advantage in comparison to other research on person-situation transactions: One can measure the person (i.e., the actor) and the situation (i.e., the interaction partner) in exactly the same terms. Interaction state variance components as well as their relations among each other and with other variables are described in detail in the Social Relations Model both from a conceptual and methodological point of view (Kenny, 1994; see Back and Kenny, 2010 for an accessible summary).

Of course, contexts in which social interactions take place can still also vary concerning aspects that are independent of the interaction partner. This can include further objective environmental cues (e.g., the degree of multi-sensory stimulation, the presence of task-related cues, the number of present individuals) that shape the way situations are 
construed (e.g., as stressful, achievement-related, or public). Both the objective cues and the subjective situation construals (see Rauthmann, Sherman, \& Funder, 2015, for a detailed framework) can have an influence on social interaction states of all interaction partners. They can also interact with the actor, partner, and relationship sources of variance, leading to an even more complex variance decomposition including actor, partner, relationship, and context characteristics as well as all of their statistical interactions as sources of interaction state variability. In this chapter, however, I will mostly focus on environmental aspects as provided by the social interaction partner.

The basic flow of processes according to lens model approaches and the componential nature of states as outlined in the Social Relations Model can, in principle, be applied to any state content. There are, however, typical kinds of state dimensions that are particularly prevalent and relevant in social interactions. Regarding interaction behaviors as well as self-, other-, and meta-perceptions during social interactions, the meta-concepts of Agency and Communion and their specification in the interpersonal circumplex (Abele \& Wojciszke, 2014; Bakan, 1966; Kiesler, 1983; Wiggins, 1991) constitute a very powerful framework. It allows both for a parsimonious and fine-grained representation of relevant interaction states (also see Hopwood, 2018; Roche \& Cain, this volume). According to this framework, behavioral and perceptual interaction states vary along interpersonal dimensions that can be localized within a circular structure with two main axes: A vertical agentic dimension (A+: directive, self-assured, assertive vs. A-: submissive, uncertain, shy) and a horizontal communal dimension (C+: warm, friendly, empathic vs. C-: cold, hostile, quarrelsome). Further dimensions can be specified as rotations of theses axes (see Figure 2, Panel A). Typically, this includes a dimension from the low left to the up right (A-C-: reserved, aloof, introverted vs. A+C+: sociable, gregarious, communicative) and a dimension from the up left to the low right (A+C-: arrogant, calculating, egoistic vs. A-C+: humble, ingenuous, honest). The idea is that each interpersonal behavior and perception can be described as a value on one 
of these dimensions; or in other words, each behavior and perception within a social interaction can be localized within the circular structure by its angular placement (what behavioral or perceptual content it refers to) and its vector length (how much the behavior is expressed or the perception is experienced, respectively).

Regarding affect states during social interactions, a similar circular structure has been proposed along the two main axes activation (i.e., how alert versus fatigued an affect state is experienced) and valence (i.e., how positive versus negative an affect state is experienced). Interpersonally relevant affective states can also be localized within this circumplex model of affect (Russel, 1980; Yik, Russel, \& Steiger, 2011). As shown in Panel B of Figure 1, this includes high activation and high valence affect states (joy, enthusiasm); low activation and high valence affect states (contentment, peacefulness); low activation and low valence affect states (disappointment, sadness); and high activation and low valence affect states (anger, distress)

- Fig. 2 here -

\section{The PERSOC Framework:}

\section{Understanding Social Interaction Process Chains}

\section{and Their Relation to Personality Expression, Consequences and Development}

PERSOC (Back, Baumert et al., 2011) is a unified framework to understand the interplay of PERsonality and SOCial relationships. It provides basic principles and a glossary of interaction components and process aspects and can be applied to all sorts of personality aspects (with regard to different content domains and levels of aggregation), relationship types (e.g., romantic relationships, friendships, family, work, and everyday relationships), and acquaintance levels (from zero to long-term acquaintance, pertaining to relationship selection, building, maintenance and termination stages). As such, PERSOC works as a general heuristic to describe, test, refine, and build up more circumscribed theories and specific hypotheses 
about how exactly concrete personality aspects express, exert their influence, and develop in a given relationship context.

\section{PERSOC principles}

In line with transactional approaches to personality and personality development (Mund \& Neyer, this volume; Neyer, Mund, Zimmermann, \& Wrzus, 2014; Reitz, Zimmermann, Hutteman, Specht, \& Neyer, 2014; Roberts, Wood, \& Smith, 2005; Swann \& Bosson, 2008), PERSOC puts a strong emphasis on the mutual connections between personality and social relationships as well as their longitudinal influences on each other over time. A number of such relations have been described in the empirical literature (e.g., Back \& Vazire, 2015, for an overview). Personality, as people's tendencies to act and experience in particular ways that differ from those of other individuals, are closely connected to relationships, as tendencies of dyads to behave and experience in particular ways that differ from their relations to others. The way we typically are with others can be understood as main expressions of our personality, and it influences how many and what kind of social relationships we develop (i.e., with whom we are with). These relationships, in turn, feed back into the development of our social identities and into the ways we act and experience the world around as (i.e., our personality).

PERSOC includes individual dispositions (IDs) and relationship dispositions (RDs) as constructs that represent personality and relationships on a latent trait level. These dispositions are thought to be internally stored in people's cognitive-affective-biological systems. IDs pertain to stable mental representations of oneself as well as biological structures that predispose to certain ways of thinking, feeling, and wanting. RDs pertain to stable mental representations of specific others. IDs and RDs are interdependent already on an internal latent trait level because they partially resort to the same representations (e.g., having a negative sense of oneself goes along with representing one's social environment as negative) and because RDs can be integrated as mental representations of oneself (i.e., as an ID) if they 
are very important to oneself (e.g., as a part of one's personal narrative) or if they generalize to many social partners (e.g., as one's concept of the generalized other).

According to PERSOC, the expression and mutual development of these dispositions is driven by social interactions and the individual and relational differences shown therein. Social interactions take place in social interaction units (SIUs), which are situations with a roughly defined starting and ending point in which individuals are aware of and react to each other. SIUs such as meetings, discussions, joint actions, chats, or brief encounters can be thought of as the building blocks that define and structure our social lives. Personality and relationship differences show themselves in SIUs, they influence each other via SIUs, and develop (stabilize and/or change) through SIUs. Please note that this conceptualization of SIUs including the states and state processes it encompasses (see below) has a strong resemblance to the concept of the interpersonal situation in interpersonal theory (Dawood, Dowgwillo, Wu, \& Pincus, 2018; Hopwood, 2018; Pincus et al., in press; also see Roche \& Cain, this volume).

SIUs encompass the interaction behaviors and interpersonal perceptions of all individuals included in the situations. With "interaction behaviors" I refer to all overt state expressions that are produced during the interaction by one interaction partner and that are in principle directly observable with normal human sensory perception of another interaction partner during this interaction. This includes expressed verbal content (e.g., disagreeing with an argument, communicating a decision), para-verbal aspects of one's voice (e.g., high volume and pitch), non-verbal behavioral expressions (e.g., frowning, expressive gestures, dominant posture, touching), and physiological reactions that are directly observable (e.g., blushing). Complex behavioral reactions (e.g., defensive behavior) often combine multiple of such expressions (e.g., justification of one's position, irritated voice, crossed arms) and often gain part of their meaning by their relation to previous behaviors of the interaction partner (e.g., challenging a position). In mediated interaction contexts (e.g., a phone call, an online 
chat, a poker or another economic game) some of these behavioral aspects are less or not observable (e.g., no non-verbal behaviors in a phone call), some are transferred in an indirect way (e.g., interpersonally relevant decisions are transferred as written information or via signs that carry meaning such as units of money) and some are partially communicated via placeholders (e.g., exclamation marks as a placeholder for para-verbal expressions; emoticons as placeholders for non-verbal expressions). Given the prime importance of differentiating between overtly observable states and not directly observable experiential states for understanding interaction processes, I regard it as very important to restrict the label behavior to those states that refer to variations in these overt interaction state expressions. In addition, one might consider behavioral equivalents such as physical appearances (e.g., physical attractiveness of face; flashiness of clothing) and behavioral residues and identity claims of one or more interactions partners that are observable in the interaction environment (e.g., a disorganized desk, a poster with one's favorite band; e.g., Gosling, Gaddis, \& Vazire, 2008). Such information is also produced by the organism of one interaction partner and observable by the other but it is not produced within the SIU itself.

When defined broadly, interpersonal perceptions include all sorts of accompanying experiential responses (affective, cognitive, and motivational) and refer to other-perceptions (e.g., inferences about others personality or intentions, liking of others), evaluations of the interaction itself (e.g., regarding how smoothly it flows, feeling more or less well in the interaction), meta-perceptions (e.g., feeling valued, thinking that one comes across as snobbish), and self-perceptions (e.g., seeing oneself as passive, feeling ashamed or proud, aiming at a deeper conversation). Both the expression of behaviors and interpersonal perception processes can take place on more controlled and more automatic process levels (Back \& Nestler, 2017; Back, Schmukle, \& Egloff, 2009; Hirschmüller, Egloff, Nestler, \& Back, 2013; also see Perugini, Hagemeyer, Wrzus, \& Back, this volume). 
The described types of state variables that typically are expressed during social interactions do so via systematic process chains: Interaction states do not just pop up out of nowhere but are systematically related to preceding and subsequent interaction states. Together these systematically related interaction states form a continuous flow of social experiences and behavioral action. Following the general idea that "thoughts do not travel" (Sperber \& Wilson, 1986), the lens model as a core process logic (Back \& Nestler, 2016; Nestler \& Back, 2013), and the "behavioral field" as described in the concept of the interpersonal situation (Hopwood, 2018; Pincus et al., in press; also see Roche \& Cain, this volume), observable interaction behaviors and the way they are perceived by interaction partners are the key interface elements that mediate between the separate mental systems of interaction partners. In other words, self-related cognitions, affective responses, metaperceived valuations, and so forth of one interaction partner exert their influence on the respective experiences of the other interaction partner via their effects on the triggering and expression of observable behaviors. These behaviors, in turn, are then perceived by the interaction partner, thereby entering his/her mental system. Behaviors should, therefore, not be understood as direct responses to interaction partners behaviors since they need to be perceived before (behavioral blindness principle). Similarly, interpersonal perceptions should not be understood as direct responses to interaction partners interpersonal perceptions because they first need to lead to observable behavioral expressions (perceptual invisibility principle). In its most generic form a typical interaction process chain, thus, takes the form IPP_A $\rightarrow$ BEH_A $\rightarrow$ IPP_B $\rightarrow$ BEH_B $\rightarrow$ IPP_A, with IPP referring to all sorts of interpersonal perceptions, $\mathrm{BEH}$ to all sorts of interaction behaviors, and $\mathrm{A}$ and $\mathrm{B}$ being different individuals.

Processes among interpersonal perception variables within the mental system of one interaction partner (i.e., the IPP element) can be further differentiated. For example, perceiving a less positive evaluation by someone might lead to the experience of shame or 
anger which then triggers withdrawn or antagonistic behavioral expressions. These behaviors lead to being perceived as disinterested or arrogant which fosters negative other-perceptions and annoyance in the interaction partner. This results in less warm or even rejecting interaction partner behaviors and thus strengthens a person's negative interaction experiences. As another example, perceiving someone as weak might lead to perceiving oneself as superior and to feeling self-assured which might result in the expression of assertive behaviors. These behaviors lead to being seen as dominant, which goes along with feelings of intimidation and less experience of own aspirations by the interaction partner. This results in the acceptance of lower-status positions and the expression of submissive behaviors. The rich variety of potential SIUs across social interaction contexts can be represented by such specified chains of interaction states that are restricted by the blindness of interaction behaviors and the invisibility of experiential interaction states (i.e., interpersonal perceptions).

Even within a well-circumscribed interaction context (e.g., a structured selection interview; a therapeutic session; a date in a bar), the expressed levels of interaction states and, thereby, the process chains that unfold vary vastly across interactions. When moving from the general description of such process chains and the description of single interactions to the systematic explanation of observable differences across interactions, we need to consider and incorporate the componential nature of interaction states. Following the Social Relations Model (Back \& Kenny, 2010; Kenny, 1994), each interaction behavior can be conceptualized as the result of actor tendencies (individuals behave differently in social interactions), partner tendencies (individuals evoke different behaviors in interaction partners), and relationship tendencies (in the given dyad one shows specific behaviors that are different from these individual trends). Similarly, each interpersonal perception can be understood as the result of perceiver tendencies (individuals perceive others differently, feel and think differently in the presence of interaction partners, and have different meta-perceptions), target tendencies (individuals are seen differently by their interaction partners and evoke different feelings, 
cognitions, and meta-perceptions), and relationship tendencies (in the given dyad one has specific perceptions that are different from these individual trends).

Given the differentiation of these interaction state components, the interaction process chains outlined above can now be described on both an (a) individual level capturing processes that generalize across interaction partners and characterize interindividual differences (i.e., personality differences) and (b) a dyadic level capturing processes that are specific to a given dyad and characterize inter-dyadic differences (i.e., relationship differences; see Figure 3). On an individual level, and starting from the perceiver's perspective, the tendency to generally perceive others as weak, for example, might relate to a general feeling of superiority and self-assuredness that relates to an assertive or even arrogant behavioral style. Such behavior, in turn, lead to being generally seen as dominant which is associated with interaction partners feeling intimidated and having fewer own aspirations. This results in interaction partners typical behaving in a submissive way and accepting lowerstatus positions (i.e., granting one social resources). The same flow of processes across variables can also be analyzed starting from the target's perspective: The tendency of a target to be seen as weak is related to others generally feeling superior and self-assured when interacting with the target. This explains why he/she evokes assertive and arrogant behavior in others. As a result s/he often feels intimidated and does not aspire to lead an interaction which is why s/he behaves submissive and accepts a lower-status position (i.e., grants others social resources). Finally, on a relational level, specifically perceiving someone as weak (more than on perceives others as weak and more than this individual is perceived as weak in general) is related to unique feelings of superiority and self-assuredness towards this person. This leads to uniquely behaving dominant and arrogant towards this person. This might then lead to a unique intimidation and lack of aspiration of this person resulting in uniquely submissive reactions and the unique provision of social resources. A complementary relational flow of 
processes can be described starting from uniquely being perceived as weak by a specific individual (see Figure 3).

- Fig. 3 -

The outlined principles and processes have straightforward implications for our understanding of personality in general. Moving beyond a perspective on personality as the profile of latent trait scores, PERSOC allows for a more specific definition of the distinct ingredients that make up the broad concept of personality from a more dynamic social interaction perspective. Specifically, following the PERSOC framework, personality can be defined as individual differences in "how people are biologically wired and how they represent themselves (ID), how people are represented by others (reputations), and are generally perceived by others in social interactions (target effects for interpersonal perception), how people generally perceive others in social interactions (perceiver effects for interpersonal perception), how people generally act (actor effects for social behaviour) and how others generally act towards them in social interactions (partner effect for social behaviour)" (Back et al., 2011; p. 102). I will now apply this logic to describe the expression, consequences, and development of personality, providing a more dynamic understanding of these key topics of personality research.

\section{PERSOC and the expression of personality}

Personality can express at multiple stages in the outlined process chains. Individual differences in narcissism might, for example, express in differences in assertive and arrogant behaviors (actor effects) as well as in differences in perceiving others as weak and in feeling superior (perceiver effects). Shyness might relate to differences in acting submissively and feeling intimidated. Personality as reputations (i.e., the way people are generally seen by others) can express as partner and target effects of others. Having a reputation as a leader might, for example, relate to interaction partners generally behaving submissively and to generally being seen as dominant. A reputation as a follower might, instead, relate to 
generally being perceived as weak and to assertive and arrogant behaviors of interaction partners. Relations between the personalities of two interaction partners can also be expressed in interaction states. Dissimilarity in the dominance of two individuals might, for example, relate to a unique perception of weakness of the more dominant individual towards the less dominant one. It has, however, to be kept in mind that (dis)similarity as any relation between individual dispositions is not a psychological entity per se (as it reflects a relation between concepts that are represented in different mental systems) and that "effects" of such personality relations are epiphenomena (i.e., by-products of more specific ongoing relational processes). In our example, the dissimilarity effect might be broken down by unique cueperception processes related to dominance: The dominant individual uniquely perceives submissive behavior (that is negatively influenced by dominance) as weak. Personality can, thus, affect various kinds of variables in process chains. Each of these influences can via the above described flow of interaction processes influence subsequent components, thereby affecting the whole interaction and its outcomes.

\section{PERSOC and the social consequences of personality}

Following this logic, one can also provide fine-grained answers to the question why personality traits relate to certain social outcomes such as relationship satisfaction, social status, or number of friends. That is, the PERSOC model helps to better understand the social consequences of personality (Back, 2015; Back \& Vazire, 2015; also see Figure 3). A personality trait will relate to a social outcome to the degree it triggers process chains that include state variables that are directly linked to a social outcome. Such multiple-step mediational pathways can be more or less complex. Let's first consider effects of traits (e.g., agreeableness) on social outcomes that are defined by one's own person (e.g., own relationship satisfaction). Such effects can be explained via effects on tendencies to perceive other's reactions in certain ways (e.g., to perceive others as more or less friendly). These perceptions cause affective responses that are linked to the social outcome (e.g., feeling 
accepted and being satisfied with one's relationships). In addition, such effects can be due to tendencies to act in certain ways (e.g., acting more warm and modest). These actions can then lead to being perceived in certain ways (e.g., as friendly), that triggers certain reactions in others (e.g., equally warm behavior). These social reactions, in turn, are perceived in certain ways (e.g., as friendly) which has the above described effects on affective responses.

Effects of traits on outcomes defined by one's social environment can be explained via tendencies to act in certain ways and to be perceived and evaluated accordingly. The lower social status of shy individuals might, for example, be explained by their tendency to act less self-assured. This leads to being seen as submissive and non-assertive which triggers more negative social evaluations of inferiority and reduces the odds of being granted social resources. Instead or in addition to this, the process pathway explaining the effect of shyness on social status might also start one step earlier, that is, with perceptual tendencies: Shy people might chronically tend to view others as domineering which then translates into their less self-assured behavior, then causing the described reactions in others.

Individual differences in other outcomes such as the number of friends are defined by reaction of both one's own person and the social partners: To have a lot of friends, one has to accept more friendships and to be accepted as a friend more often. The underlying process pathways explaining the effects of traits on such outcomes are very likely combinations of the above-mentioned pathways: Extraverts, for example, might have more friends, first, because they tend to perceive others as more interesting which makes them accept more friendships. Second, extraverts might act in more expressive ways which creates impressions of being seen more interesting which makes others accept them more often as friends. This evoked impression might, third, make others act in more expressive ways themselves, reinforcing extraverts' tendency to perceive others as interesting.

In analogous ways, one can explain effects of a personality relation such as a similarity in trait levels (e.g., extraversion similarity) or of combinations of trait scores across traits 
(e.g., low agreeableness-high neuroticism combination) on relationship outcomes that are specific for a given dyad (e.g., unique relationship satisfaction; unique amount of relationship conflict). In any case, personality relations exert their influence on one or both relationship partners, via an idiosyncratic perception of the given partner's behavior. This unique perception is shaped by the first personality trait and the behavior is shaped by the second personality trait of the personality relation. Extraverts might particularly perceive expressive behaviors, that is, behaviors typically expressed by other extraverts, as interesting. Those high in neuroticism might be uniquely stressed out by provocative behaviors that are typical for those low in agreeableness. These unique perceptions can then directly lead to unique affective reactions that are linked to the relational outcomes (e.g., seeing someone as particularly interesting is linked to being uniquely satisfied with the respective relationship; being uniquely stressed out by someone is linked to the perception of conflict).

As described for the individual-level pathways, such unique perceptions can also exert an indirect influence via the triggering of unique behavioral expressions. These unique behaviors then lead to uniquely being perceived in certain ways which then triggers affective reactions and relational outcomes on the partner's side. Finally, such unique experiential partner reactions can additionally reinforce one's own unique perceptions via the partner's behavioral reactions. If an extraverted actor perceives the expressive behaviors of another extravert as particularly interesting, this might lead to uniquely communicative behaviors towards this partner. This unique behavior then leads to unique perceptions of interest and associated relationship satisfaction in the partner. This might, moreover, lead to more communicative partner behaviors which reinforces the unique interest perceptions in the actor. If a neurotic actor is uniquely stressed out in response to the provocative actions of a disagreeable partner, this might lead to uniquely awkward and nervous behaviors towards this partner. This leads to negative affective reactions and the unique perceptions of conflict in the partner. If, in addition, the disagreeable person is uniquely bugged out by awkward and 
nervous behaviors (that are typical for neurotic partners and particularly for neurotic partners in response to provocative actions that are typical for disagreeable actors), and react with even more antagonistic behavior, this might result in vicious cycles characterized by increasing relational tension and conflict.

\section{PERSOC and the development of personality}

In the same way social interaction processes drive personality effects on social relationships, they are thought to drive stabilizations and changes in personality, that is, personality development. This reasoning is in line with bottom-up approaches to personality development more generally, such as the sociogenomic model (Roberts, 2009; Roberts \& Jackson, 2008), the TESSERA model (Wrzus, this volume; Wrzus, \& Roberts, 2017), and the state process model of personality development (Geukes, van Zalk, \& Back, 2017, 2018). First of all, by definition, personality development directly follows from stabilization and changes in the ways individuals regularly experience and behave during social interactions (because personality is defined by these regularities). Any behavior someone expresses and/or any interpersonal perception someone experiences that deviates from one's average way of experiencing and behaving can initiate personality development as soon as it perpetuates in the following SIUs. Behavioral expressions and interpersonal perceptions that reinstate previous interaction state levels, in turn, will contribute to the stabilization of personality. Importantly, due to the systematic process chains described above, changes and stabilizations in one interaction state tend to go along with changes and stabilizations in other states belonging to the same personality aspect. If an actor who tends to be reclusive and shy acts slightly more expressive (e.g., because s/he is in an exceptionally good mood), this can provoke more positive social feedback, which can lead the actor to perceive others as less intimidating and more interesting, further strengthening a more expressive behavior $-\mathrm{a}$ slightly more extraverted process chain starts to evolve. This change can be initiated at other points in the process chain as well. The actor might, for example, also be perceived as more 
socially attractive than usual in a given SIU (e.g., because s/he got a new haircut). This would lead others to show more interest in him/her which leads to more social interest and less withdrawal in the actor.

One way in which longer-term effects (either stabilizing or changing) of such social interaction states across SIUs can be realized is via their effects on IDs, that is, because they affect the way people generally represent themselves and others and/or because they affect biological structures, both of which then provide new default settings for the expression and experience of future social interaction states. Starting to perceive others as weak as a consequence of one's newly cultivated domineering behavior, and the respective perceptions and submissive behaviors by others, for example, might foster the development of a more general idea of other humans (the generalized other; e.g., Bowlby, 1988; Kenny, 1994) as subordinate and of oneself as superior. These IDs, then, increase the odds that one behaves more domineering and perceives others as weak in future SIUs. Another key domain of state variables in this context are meta-perceptions (Kenny, 1994). Such reflected appraisals (Shrauger \& Schoeneman, 1979) have a strong influence on how we see ourselves. Changes in how we meta-perceive the impressions we make on others during SIUs (which can be justified or not) can, therefore, change our general self-concept. If someone repeatedly has the impression that others view him/her as particularly cooperative, s/he might develop a selfconcept as an agreeable person, which, in turn, might function as a background against which this person evaluates his/her own behavioral standards, influencing the degree of cooperativeness s/he expresses in future SIUs. Another prominent example of this logic is described in sociometer theory (Leary \& Downs, 1995; Leary \& Baumeister, 2000) which posits that self-esteem is a meter indicating one's degree of social inclusion. Meta-perceptions of being socially included are thus the key mechanism in this theory: The more an individual perceives to be liked by others, the more self-esteem this person will experience signaling him/her more or less satisfaction of the fundamental need to belong (Baumeister \& Leary, 
1995). Trait self-esteem, in this view, represents individual differences in people's default expectations for how well they are socially included. This default not only influences people's behavior (e.g., more expressed self-assurance) and interpersonal perceptions (e.g., actualized meta-perception of being liked) in a given SIU, it can also be shaped by interaction experiences: If people start to meta-perceive being liked less than usual, this might over the course of multiple interactions lead to a change in their default expectation and thus also in their trait self-esteem.

Finally, as described above, IDs can also develop as a consequence of changes in RDs that were driven by interaction processes. Repeatedly engaging in uniquely self-disclosing communication towards someone can, for example, lead to feeling uniquely close to this person which might lead to the development of an RD representing this person as a friend for life. This RD, in turn, might be incorporated into one's life narrative (e.g., "The time I got to know this person as a turning point in my life") as well as one's values (e.g., "having a few good friends is key in life").

\section{Interaction State Contingencies and Fluctuations}

PERSOC describes individual differences in the level of interaction state components and how these differences are connected to each other and build up individually different interaction process pathways. Also, it specifies how these differences are influenced by and influence stable personality and relationship dispositions. Individuals can, however, also differ in the strength of relations among state components, a concept known as individual differences in if-then contingencies in social-cognitive approaches (see the CAPS-framework by Mischel \& Shoda, 1995, 1998, 2008, and the Whole Trait Theory by Fleeson, and Jayawickreme, 2015, and Fleeson, this volume for detailed accounts), as interpersonal signatures (e.g. Fournier, Moskowitz, \& Zuroff, 2008), as affective/emotional reactivities in emotion and motivation research (Dufner, Arslan, Hagemeyer, Schönbrodt, Denissen, 2015; 
McClelland,1987; Robinson, 2007), and as transitional probabilities in behavioral interaction research (Bakeman \& Gottman, 1997).

Although not articulated as such, if-then contingencies play already a key role in the PERSOC framework. They are the links that build up the process pathways and explain (a) why individual differences in one state lead to individual differences in further states and (b) how dispositional differences express, develop, and exert their influence on social outcomes. The role of individual differences in such contingencies itself has, however, not yet been systematically integrated into the PERSOC framework. Contingency differences can refer to all of the links between interaction states described above. Individuals might, for example, not only differ in their tendency to see others as cold and to behave in a shy way but also in the degree to which the perception of coldness triggers one's own shyness. They might not only differ in in their tendency to see others as domineering, to experience negative affect, and to behave in a quarrelsome way but also in the degrees to which the perception of dominance triggers negative affect and to which negative affect, in turn, triggers one's own quarrelsomeness. Similarly, all of the other above-mentioned links between interaction states of typical process pathways and chains can be subject to systematic individual differences. A comprehensive understanding of interpersonal personality traits and how they are expressed needs to incorporate such individual differences in interaction state contingencies. Agreeableness might not only be characterized by a higher propensity to engage in warm and modest behaviors and to perceive others as trustworthy, but also by a stronger reactivity with positive affect in response to helping behavior and a higher discomfort in response to metaperceived suffering. Extraversion might not only be characterized by levels of expressivity, dominance, and positive affect, but also by the strength of the link between social stimulation and positive affect and between positive affect and expressive non-verbal behaviors.

Considering individual differences in interaction state contingencies in addition to interaction state levels also has important implications for the analysis of personality 
consequences and development. Of two individuals with a similar pessimistic view on others' intentions and the same overall tendency for expressing aggressive behavior, the one with a stronger link between negative perceptions and aggressive behavior will, in many social situations, end up showing more aggressive behaviors which might result in less favorable social reactions and reputations. A decrease in antagonism might, in turn, be initiated not only by reducing negative views of others or one's aggressive tendencies, but also by an uncoupling of negative affect and aggressive behavior.

The strength of if-then contingencies can also be conceptualized as the accentuation or differentiatedness of the within-person profile of interaction state "thens" across interaction state "ifs": The more people react differently with affect to different other perceptions, the stronger their perception-affect contingency; the more they perceive others differently in response to different expressed cues, the stronger their respective cue-perception reactivity. In addition to being more or less accentuated (individual differences in contingency strength), interaction state contingencies can also be more or less stable (individual differences in contingency stability). Both types of between-person contingency differences underlie and explain interindividual differences in intraindividual variability, which are meanwhile prominent dynamic extensions of the personality vocabulary (Fleeson, 2004; Vazire, \& Sherman, 2017). Density distributions (Fleeson, 2001), for example, not only include mean levels for each individual in a given interaction state but also variability differences. Considering interaction states within the interpersonal circumplex allows for even more differentiated global variability indices, including individual differences in flux (variability in the expressed level of a specific interpersonal behavior or perception), pulse (variability in the extremity of expressed interpersonal behaviors or perceptions), and spin (variability in the kind of expressed interpersonal behaviors or perceptions; Sadikaj, Moskowitz, \& Zuroff, 2017; Moskowitz \& Zuroff, 2004). 
Importantly, these descriptions of fluctuation differences are typically simply measured across occasions and thus only represent the overall variability of "thens" (see descriptive part in WTT; Fleeson, this volume) without considering the "if"s. These individual differences in variabilities should, thus, not be regarded as process differences themselves but as by-products of individual differences in processes - specifically, as the result of individual differences in the strength and stability of if-then contingencies (see explanatory part in WTT; Fleeson, this volume).

When the "if" refers to a social cue that can be used to differentiate contexts (e.g., being in an accepting versus rejecting social situation; being in the role of a colleague versus a partner), the strength and stability of if-then contingencies can be directly related to the explanation of variabilities across similar contexts (within-context fluctuations) and across different contexts (cross-context fluctuations; Geukes, Nestler, Hutteman, Küfner, \& Back, 2017). A higher cross-context variability should be a by-product of high contingency strength and thus more accentuated interaction state-profile for a particular individual. An individual who reacts more extremely with positive versus negative affect to perceived smiling versus frowning of others has a higher affect variability across these different social contexts. Someone who shows the same amount of cheerfulness in the role of a colleague or a friend has a weak role-behavior contingency and a low variability across these role contexts. A higher within-context variability, in contrast, should be a by-product of less stable interaction state contingencies. If someone reacts with very positive affect to smiling and very negative affect to frowning in one situation but shows a relatively neutral affect to smiling and frowning (i.e., a flat profile; a weak contingency) in another situation, s/he would have an unstable state profile and a high variability within both contexts. Someone who always acts very cheerful when with friends and always shows a medium amount of cheerfulness when with colleagues would have a stable role-behavior contingency and a low variability within 
each role-context. The relation between social interaction state contingencies and social interaction state variabilities is illustrated in Figure 4.

- Fig. 4 -

Interaction state variabilities are dynamic proxy measures of ongoing interaction processes but are not processes themselves; they need to be broken down by close investigations of the interaction state contingencies that produce them. Thus, to understand individual differences in interaction state variabilities (e.g., why some people fluctuate more in their cheerfulness, while others show a stable expression of low or high cheerfulness), one needs to analyze individual differences in how strongly cheerfulness is linked to varying characteristics of the social context and the perceptions thereof.

\section{Empirical Findings Regarding Individual Differences in Social Interaction States}

While there are few available data and empirical analyses that capture all complexities described in the PERSOC framework (see Geukes et al, 2019), there are several streams of research that indirectly speak to the role of both experiential (perceptions and affect) and behavioral interaction state components for personality research. This regards the reliability and content-wise structures of an interaction state component domain (i.e., Are there reliable actor, perceiver, partner, and target effect differences and how many distinct dimensions are there?) as well as the relation of interaction state components with other more established trait measures of personality (i.e., What are the personality correlates of these components?). Research on individual differences in state contingencies (also see Roche \& Cain, this volume) is similarly scattered across research fields, with almost no systematic research on the structure of the wide variety of possible contingency measures, selective findings regarding specific trait measures and specific contingencies, and few effects being sufficiently replicated as of yet. A comprehensive review of empirical findings on individual differences in interaction state components and contingencies is beyond the scope of the present chapter. 
Instead, I will highlight some common findings and key investigations as illustrative examples and interpret them in terms of the PERSOC framework.

\section{Differences in interaction state levels}

Differences in own interaction behavior (Actor Effects). If measured (a) on a sufficiently aggregated, psychologically meaningful level and (b) in relevant social situations that allow for and potentially trigger the expression of behavioral differences, individual differences in interaction behaviors (i.e., actor effects) are substantially consistent across situations, interaction partners, and time (Borkenau et al., 2004; Funder \& Colvin, 1991; Leikas, Lönnqvist, \& Verkasalo, 2012; Leising \& Bleidorn, 2011). That is, people differ in their general tendencies to behave nervous, self-assured, friendly, dominant, cheerful, shy, arrogant, or modest in social interactions. These differences tend to account for as much or more variance in behavioral expressions as situational features (e.g., the interaction partner; Kenny, 1994). In one particularly elegant study, Leikas and colleagues (2012) videotaped and coded dyadic behaviors with professional actors who interacted with participants in four roles: a dominant, submissive, agreeable, and quarrelsome role (reflecting the two poles of the Agency and Communion dimensions of the IPC). Behavioral differences between participants were substantially consistent across situations (i.e., across the different roles their interaction partner, that is the professional actor, displayed) and accounted for more variance then differences between situations. Particularly strong and consistent between-person differences were found for the micro-level behaviors gesturing, open vs. closed posture, orientation toward vs. away from the actor, and smiling/laughing, and molar-level ratings of expressed positive and negative affect, enjoyment, and awkwardness.

Based on experience-sampling designs, Fleeson (2001; see Fleeson 2004, for an overview) has shown that between-person differences in self-reported Big Five behaviors in people's everyday life are substantially stable, and this includes domains relevant to interpersonal behavior. In three studies (Fleeson, 2001), differences between participants in 
mean behavioral tendencies sampled in one week correlated very strongly with mean behavioral tendencies sampled in another week (stabilities amounted to .94 / .97 / .98 for agreeable, and $.90 / .95 / .91$ for extraverted behavior, for example) - despite large withinperson variabilities in each week. The strong stability of mean behavioral tendencies was also confirmed in a 20-day event-contingent recording study on interpersonal behaviors in which participants reported on their own behavior following each social interaction of at least 5-min duration (Fournier et al., 2008). Stabilities amounted to .76 for dominant behavior, .77 for agreeable behavior, .82 for submissive behavior, and .83 for quarrelsome behavior.

Amazingly few studies systematically analyzed the structure of individual differences in actually observed interpersonal behavior. In one of the rare studies, Leising and Bleidorn (2011) videotaped participants in 17 interpersonal role plays with a confederate (e.g., initiate a conversation, confront someone, ask for emotional support, present yourself positively). Factor analyses based on behavioral ratings of the videotaped behaviors confirmed Agency (e.g., acting dominant, self-assured, talkative, and determined) and Communion (e.g., acting polite, soft-hearted, peaceful, and conforming) as the two basic dimensions of interpersonal behavior but also revealed a third Emotional Stability factor (e.g., acting stable, relaxed, robust, and secure).

The relation between standard questionnaire-based personality trait measures and individual differences in actually expressed social behavior has been examined in different research traditions, including research on the predictive validity of personality measures and the validation of personality process models (Back et al., 2013; Back et al., 2009; Borkenau et al., 2004; Funder, Furr, \& Colvin, 2000; Vazire, 2010) as well as lens model research on the behavioral cues by which personality is expressed (Back \& Nestler, 2016; Breil, Osterholz, Nestler, \& Back, in press). Extraversion is the trait that most consistently and most strongly relates to measures of overt social behavior, including a more neat and stylish physical appearance and behavioral indicators such as smiling, expressive gestures, self-assured 
posture and body movements, expressive and loud voice, amount of speaking, and the use of humor (Back et al., 2009, 2011; Eaton \& Funder, 2003; Levesque \& Kenny, 1993; Riggio \& Riggio, 2002; Scherer, 1978). Similar relations to self-assured and expressive behaviors have been reported for other agentic traits such as narcissistic admiration (Back et al., 2013; Leckelt, Küfner, Nestler, \& Back, 2015). Agreeableness and other communal versus antagonistic traits (e.g., narcissistic rivalry) have been related to more attentive, modest, and friendly and less arrogant, combative, and aggressive behaviors as well as to social orientation in verbal content (Back et al., 2013; Back et al., 2009; Berry \& Hansen, 2000; Borkenau \& Liebler, 1992; Holtzman, Vazire, Mehl, 2010; Küfner, Back, Nestler, \& Egloff, 2010; Leckelt et al., 2015). Neuroticism has been related to more tensed and nervous postures, facial expressions, and gestures; a more awkward interpersonal style; a restricted, less fluent, and nervous voice; and more negative verbal content (Asendorpf, 1988; Back et al., 2009; Creed \& Funder, 1997; Pennebaker \& King, 1999; Pilkonis, 1977; Riggio \& Riggio, 2002).

In accordance with trait activation theory and the concept of trait relevance (Tett, this volume; Tett, \& Burnett, 2003; Tett \& Guterman, 2000; Funder, 1999), these behavioral predictions are found if individuals are observed in social situations that are relevant to a given personality domain because the respective individual differences are activated. While differences in extraversion (vs. introversion) are expressed in almost any social interaction context, differences in neuroticism (vs. emotional stability) are only expressed in socially stressful interactions and differences in agreeableness (vs. antagonism) only in situations in which "the interests or concerns of others may be at least as salient as one's own and there is wide latitude for either amplifying or minimizing interpersonal conflict" (Back, Schmukle, \& Egloff, p. 534; also see Back, Küfner, \& Leckelt, 2018; Hirschmüller, Egloff, Schmukle, Nestler, \& Back, 2015).

In addition, experience-sampling research shows that personality trait measures robustly predict the mean level of self-reported personality in the moment (Fleeson \& 
Gallagher, 2009), including extraverted, agreeable, and neurotic behaviors as reported after engaging in social interactions. In a recent experience-sampling study that extended the considered social perspectives, it could be shown that trait extraversion predicted both selfand interaction partner-reported sociable behavior (Breil et al., 2019). Together with the laboratory studies summarized above, these findings underline that people reliably differ with regard to the interpersonal behaviors they express during social interactions and that these differences are related to people's self-concept (i.e. their IDs).

Differences in interaction partner's behavior (Partner Effects). Partner effects (i.e., differences in how interaction partners behave towards you) are necessarily more complex since they refer to effects that are mediated by further mental processing of interaction partners and their behavior expression: Individuals differ in how others act towards them because they themselves show certain behaviors and appearances (actor effects) that lead others to perceive them in certain ways (target effects, see below), which then triggers the interaction partners' behavior. Consequently, the amount of partner variance in interpersonal behaviors is comparatively low and almost absent in many cases. Also, there are few consistent correlates of partner effect differences (Kenny, \& Malloy, 1988; Kenny, Mohr, \& Levesque, 2001).

Given the more complex process pathways implied, different interaction partners might only then evoke behavioral differences in partners when they themselves very strongly and clearly differ from each other. This might, for example, be observable in case of clear role differences among interaction partners (e.g., supervisor vs. subordinate role) that are directly related to different partner actions (e.g., giving directions vs. taking orders). These partner actions are in turn clearly perceived as such and, then, have clear implications for the expression of different actor behaviors (e.g., acting less dominant when interacting with a supervisor). In the above-mentioned study by Leikas and colleagues (2012), the role the interaction partner displayed (dominant, submissive, agreeable, and quarrelsome) accounted 
for a substantial share of actors behavioral differences at least for some micro-level behaviors. Specifically, depending on whom they interacted with, participants showed different amount of speaking, number of questions, verbal acknowledgments, number and duration of mutual gazes, and speaking turns. Stronger partner effects on behavior might also be evoked in interaction contexts in which behavioral differences are expressed in clearly distinguishable ways, despite the existence of consensually shared ideas regarding what sort of behavior is interpersonally expected. In these cases, deviations from shared expectations would be consensually salient, evoking similar reactions to such social partners (i.e., evoking partner variance). In negotiations, for example, in which there is a certain socially shared expectation regarding mutual benefits of a fair outcome, both overly selfish as well as overly generous reactions of partners (that nevertheless occur, e.g., Hilbig, Glöckner, \& Zettler, 2014) should be noticed and perceived similarly by most actors which might lead to similar (dis-)pleased reactions toward different partners (i.e., partner variance in interaction behavior).

Differences in own interpersonal perceptions and affect (Perceiver Effects). Across social interactions, people also differ in their general judgmental and affective tendencies (Kenny, 1994). Perceiver effects in interpersonal perceptions refer to differences in how people view their interaction partners in general. Such perceiver effect differences are, for example, key explanatory variables in theoretical accounts on the development of trust (Erikson, 1959), attachment (Fraley, 2002), depression (Beck, 1979), and personality disorders (Hopwood, 2018; Hopwood, Schade, Krueger, Wright, \& Markon, 2013). Previous empirical research shows that judgmental tendencies are stable across time and pertain to both positivity and trait-specific differences (Rau, Carlson, et al., in press; Srivastava, Guglielmo, \& Beer, 2010; Wood, Harms, \& Vazire, 2010): People differ regarding how rosy versus grumpy they perceive their interaction partners and also regarding more specific interpersonal perceptions (e.g., how much they see others as intelligent, anxious, trustworthy or dominant). Perceiver effects in interpersonal perceptions have also been related to trait measures. 
Positivity differences tend to relate to communal vs. antagonistic traits (e.g., Back et al., 2013; Back, Schmukle, \& Egloff, 2011; Rau, Nestler, Dufner, \& Nestler, in press; Wood et al., 2010; Wurst et al., 2017). In addition, according to the classic concept of assumed similarity (Cronbach, 1955; Kenny, 1994), people tend to view others as they view themselves. In line with the concept of interpersonal complementarity (Dawood et al., 2018; Sadler, Ethier, \& Woody, 2011), however, there is some evidence for stronger self-similarity perceptions in the domain of communal traits but self-dissimilarity perceptions in the domain of agentic traits (i.e., dominant individuals view others as more submissive; Dufner, Leising, \& Gebauer, 2016; Rau, Nestler, Geukes, Back, \& Dufner, 2019; Thielmann, Hilbig, \& Zettler, 2020; Tiedens, \& Jimenez, 2003). Finally, in the domain of personality pathology, there are a range of ideas and selected findings relating personality disorders to specific perceptional biases (e.g., borderline personality and perceiving abandonment, obsessive-compulsive personality and perceiving imperfection; APA, 2013; Hopwood, 2018).

Perceiver effects in affect concern individual differences in the typical level of emotional states people experience during social interactions. In line with research on positive and negative affectivity, there are stable affective differences between individuals that are closely linked to the traits extraversion and neuroticism, respectively. For example, in a recent experience-sampling study on real-life social interactions (Geukes, Nestler, Hutteman, Dufner et al., 2017; Geukes, Nestler, Hutteman, Küfner, \& Back, 2017), extraversion was related to a more positive and less negative, while neuroticism was related to a more negative mean affect (also see Lucas \& Baird, 2004; Lucas, Le, \& Dyrenforth, 2008; Rusting \& Larsen, 1997). In addition, individuals also differ in how they perceive themselves which is closely linked to affective experiences. In the above-mentioned experience-sampling study, for example, extraversion, low neuroticism, and narcissistic admiration related to a higher mean state selfesteem (also see Meier, Orth, Denissen, \& Kühnel, 2011; Zeigler-Hill et al., 2015). 


\section{Differences in interaction partners' perceptions and affect (Target Effects).}

Individuals also reliably differ in how they are perceived by others in social interactions (Kenny, 1994). In other words, there is a certain degree of consensus among perceivers in how different targets are seen. This regards both trait perceptions (i.e., how much people are seen as extraverted, agreeable, intelligent, and so forth; aka their personality reputation) as well as affective perceptions (i.e., how much people are liked by others; aka their popularity). Both kinds of target effects have been related to self-reports of targets' personality traits. For personality reputations, this regards research on the accuracy of or self-other agreement in trait judgments (i.e., How well do personality perceptions of interaction partners match the targets actual/self-reported personality?). Lens model research explains the level of accuracy/self-other agreement by the expression of behavioral cues (actor effects) and the consensual perception of these cues (target effects). The more a trait expresses in observable behavior and the more this observable behavior is used to infer a personality trait, the higher self-other agreement will be. Aspects of traits (e.g., observability, evaluativeness), information (e.g., amount and non-redundancy), targets (e.g., expressivity, stability), perceivers (e.g., intelligence, extraversion), and interactions between these factors (e.g., diagnosticity/trait*information: traits observed in trait-relevant situations) that increase the expression and utilization of valid cues moderate the degree of self-other agreement/accuracy (see Back \& Nestler, 2016; Funder, 1999; Hirschmüller, Breil, Nestler, \& Back, in press, for overviews). Applying and extending the lens model logic (Nestler \& Back, 2013), the relation of personality measures to popularity can similarly be understood as the result of a process pathway that includes behavioral expression processes (personality trait relates to actor effect behavior), interpersonal perception processes (actor effect behavior relates to target effect personality impression), and evaluation processes (target effect personality impression relates to target effect liking/attraction; Back, Schmukle, \& Egloff, 2011; Back et al., 2018; Leckelt, et a., 2015). 
Considering these pathways is crucial to understand the effects of targets' personality on the actual perceptions of their social counterparts (i.e., on the targets' actual social outcomes) as compared to abstract evaluations of perceivers of hypothetical targets (e.g., based on vignettes with varying verbal descriptions). In the latter case, relations between "targets" " characteristics only reflect the evaluation process step - how explicitly stated and perceived characteristics are evaluated by perceivers. In reality, however, these characteristics are far from being always observable and perceived as what they reflect. For example, although agreeableness is the trait most commonly judged (Ames \& Bianchi, 2008) and most positively evaluated (Anderson, 1968; Hampson, Goldberg, \& John, 1987), perceivers only achieve weak or no accuracy in their agreeableness judgments (Connelly \& Ones, 2010; Connolly, Kavanagh, \& Viswesvaran, 2007). Further, agreeableness has negligible or no effects on popularity (Back, Schmukle, \& Egloff, 2011), at least in zero- and short-term acquaintance contexts. One potential reason for this is that in such contexts, behavioral cues that are perceived as indicative of agreeableness (e.g., smiling) are, in fact, stronger expressions of extraversion while target differences in agreeableness express only in more intimate and longer-term oriented social contexts. In the context of leadership emergence, it has, for example, been shown that more extraverted individuals were chosen as leaders across social contexts while more agreeable individuals were evaluated more positively only in more cooperative interaction contexts (Lawless DesJardins, Srivastava, Küfner, \& Back, 2015).

The social context moderates the relation between target personality and social outcomes via all of the above described process steps: It can shape how much trait differences are expressed and thus observable; how expressed behaviors are perceived; and how these perceptions are evaluated. This can imply effects on more than one process pathway, allowing for fine-grained analyses of complex pattern of personality effects. Self-presentational, and short-term acquaintance contexts, for example, foster positive effects of narcissism on peer popularity via an agentic pathway (behaving self-assured and being perceived as assertive). In 
contrast, more intimate, intense, and longer-term acquaintance contexts foster negative effects of narcissism on peer popularity via an antagonistic pathway (behaving combative and being perceived as aggressive/uncommunal) (Back et al., 2018; Küfner et al., 2013; Leckelt et al., 2015; Leckelt et al., in press). Generally speaking, the more outcomes belong to the "getting ahead" domain (e.g., status, leadership emergence; evaluations in more superficial and selfpresentational short-term acquaintance contexts), the stronger are effects of agentic traits such as interpersonal dominance and extraversion. The more social outcomes belong to the "getting along” domain (e.g., perceived closeness, relationship satisfaction; evaluations in more intimate, longer-term acquaintance contexts), the stronger are effects of communal traits such as interpersonal warmth and agreeableness (Back \& Vazire, 2015). Most of the reported associations between trait measures and target effects await more detailed investigations of the specific underlying behavioral, perceptional, and evaluative processes.

\section{Differences in interaction state contingencies}

While there is an increasing amount of empirical studies on the distribution and correlates of within-person state variabilities (e.g., Vazire \& Sherman, 2017, for a recent special issue), including interaction states, there is much less personality-oriented work on the specific state-contingencies that make up these variabilities. Following the idea that personality is also reflected in individual differences in if-then contingencies, personality research needs to examine the reliability, structure, and trait correlates of these contingencies. The assumption of person $\times$ situation interactions (e.g., Endler, $\&$ Magnusson, 1976), which directly translate into individual differences in interaction state contingencies, is at the heart of a number of influential theories including Trait Activation Theory (Tett \& Burnett, 2003; Tett \& Guterman, 2000), the Cognitive-Affective Processing System model (Mischel \& Shoda, 1995; Mischel \& Shoda, 2008), and Whole Trait Theory (Fleeson \& Jayawickreme, 2015). The empirical evidence for replicable person-situation effects and robust individual 
differences in the strength of the respective state contingencies is, however, still mixed (see Rauthmann, this volume).

Variance partitioning approaches typically show that person $\times$ situation interaction variance components are comparatively large (see Lakey, 2016 for an overview). It is often far less clear, however, how much these components reflect stable individual differences in contingencies as opposed to random fluctuations. Indirectly providing evidence for the stability of underlying individual differences in interaction state contingencies, Fleeson (2001) found that individual differences in the within-person variability in self-reported behavior were substantially stable in three independent studies (e.g., .58 / .78 / .86 for agreeableness and $.59 / .80 / .85$ for extraversion; also see Fleeson, 2007 for similar findings). Similar medium-sized to high stabilities were also reported for flux, pulse, and spin variabilities regarding interpersonal behavior (Moskowitz \& Zuroff, 2004). Fleeson (2001, 2007) also reported individual differences in contingencies between experienced-sampled situation characteristics and Big Five state reports. People differed in how much they reported extraverted behavior (energy, talkativeness, and boldness) in response to anonymous (vs. more intimate) situations (Fleeson, 2007), and in response to the presence of others (Fleeson, 2001). There was also some tentative evidence that the amount of within-person variability in extraversion correlated with individual differences in these contingencies.

Few studies have to date more directly investigated the stability of individual differences in the strength of interaction state contingencies. In a classic contribution, Shoda, Mischel, \& Wright (1994) examined the stability of situation-behavior profiles among psychiatrically disturbed children attending a residential summer camp. Children's interpersonal behaviors (verbal aggression; physical aggression; whined or displayed babyish behavior; complied or gave in; talked prosocially) as well as the kind of interpersonal situation they were in (positive peer contact; teased, provoked, threatened by peer; praised by an adult; warned by an adult; punished by an adult) was recorded by camp counselors over a 
6-week period. For each behavior a profile was calculated for each child reflecting how it reacted with this behavior to each of the different interpersonal situations. The within-person stability of these situation-behavior contingencies ranged from .19 (for prosocial talk) to .47 (for verbal aggression). In another more recent field study, Smith, Shoda, Cumming, \& Smoll (2009), investigated the supportive, punitive, and instructional behaviors of youth baseball coaches in response to circumscribed game situations (winning, losing, close game). Again, significant differences in situation-behavior profiles were found with a mean stability of 46 . Borkenau, Riemann, Spinath, \& Angleitner (2006) found similar consistencies of situationbehavior profiles in a genetically-informed laboratory study in which participants (168 monozygotic and 132 dizygotic twin pairs) were observed in 15 behavioral tasks and were evaluated regarding their personality by multiple judges. The mean reliability of individual profiles across tasks amounted to .49 (agreeableness: .38; extraversion: .59). Genes accounted for $25 \%$ of the reliable person $\times$ situation variance.

Fournier et al. (2008) investigated the stability of interpersonal behavioral signatures, using a 20-day event-contingent recording design. Participants reported on their interactions in everyday life and indicated how they perceived their interaction partner and how they behaved themselves. For each behavioral domain a profile was computed for each individual reflecting how much this individual reacted with a given behavior (i.e., one's own dominant, agreeable, submissive, and quarrelsome behavior) to perceived dominance, agreeableness, submissiveness, and quarrelsomeness of others. The mean within-person correlation of these profiles were .24 for dominance, .39 for agreeableness, .32 for submissiveness, and .52 for quarrelsomeness, indicating at least some stability in the individual contingencies between perceptions of the interaction partners behavior and peoples own behavior. In another timebased 1-week experience-sampling design Sherman, Rauthmann, Brown, Serfass, \& Jones (2017) found that stabilities of individual differences in situation-based contingences were quite varied, with a mean of .31 . While individual differences in some contingencies were at 
least somewhat reliable (e.g., reliability of differences in the strength of the situation's sociality $\rightarrow$ sociability behavior contingency: .56), others were not reliable (e.g., reliability of differences in the strength of the situation's adversity $\rightarrow$ dominance behavior contingency: $.17)$.

A number of studies in laboratory contexts have reported personality correlates of interaction state contingencies (i.e., interactive effects of a trait and the if-part on the then-part of the contingency). For example, in accordance with the concept of trait relevance, it has been shown that neuroticism is observable (via nervous verbal and non-verbal behavior) in socially stressful but less so in more neutral social situations (Hirschmüller et al., 2015). In other words, the contingency between the stressfulness of the interaction unit and nervous behavior seem to be stronger for those high in neuroticism. A study by Dufner and colleagues (2015) tested the idea that individual differences in affective reactivity to circumscribed social cues underlie motive dispositions. In line with this idea, they revealed reliable individual differences in the degree to which people reacted with positive affect (captured by physiologically assessed facial muscular activity) to affiliative stimuli. Moreover, these differences were linked to affiliation motive self- and informant-reports, and picture story exercise scores. Research by Robinson and colleagues and others (see Robinson, 2007 for a review) suggests that extraverts might react more strongly with positive affect to positive events (e.g., a friendly facial expression), those high in neuroticism react more strongly with negative affect to negative events (e.g., a socially stressful encounter), and agreeable individuals react less strongly to provocation (e.g., a rude critique). The literature on such interactive effects of personality trait measures and situational aspects on experiential and behavioral states in laboratory contexts is rich but also scattered across literatures. Also, very few of these laboratory person-situation effects have been directly replicated, transferred to the observation of actual social interactions, and were based on large enough sample sizes. 
Evidence for person $\times$ situation effects on real-time expressions of experiences and behaviors (i.e., trait correlates of individual differences in situation-experience/behavior contingencies) is also mixed. Sherman and colleagues (2017) applied a 1-week time-based experience-sampling design, in which participants filled out a personality questionnaire and reported on the situation they were in (1-item DIAMONDS measures; Rauthmann \& Sherman, 2016) as well as their behaviors and feelings (state Big Five and self-esteem reports) eight times per day. Results underline the power of both situations (e.g., if the situation is perceived as being social, people act more extraverted; if the situation is perceived as being deceptive, people act less honestly/humbly) and personality traits (e.g., those high in trait extraversion act more extraverted; those high in trait honesty/humility act more honestly/humbly) in shaping everyday behavior and experiences. Few evidence was, however, found for interactive effects: Generally, personality traits did not moderate contingencies between perceived situation characteristics and behavioral and affective states. In those analyses where statistically significant interactions were found (e.g., less strong negative effect of situations' deception on honest/humble behavior for those high in trait honesty/humility), the respective effect sizes were small (also see Sherman, \& Pashler, 2019).

Other experience-sampling studies that focus on specific personality variables and more circumscribed social interaction situations found evidence for (small) person-situation interaction effects. For example, Breil and colleagues (2019) focused on the expression of sociability within social interaction situations only. Across two studies they found evidence not only for trait effects (higher sociability for extraverts) and situation effects (higher sociability in low-effort/positive/low-duty situations), but also for small trait-situation interactions (extraverts particularly showed more sociable behavior in low-effort/positive/ low-duty situations). In their Study 2, these effects were revealed for self-reported experiencesampled behavior and experience-sampling reports by the interaction partner. Geukes and colleagues (2017) found that narcissistic rivalry was related to increased fluctuation in 
experienced-sampled state self-esteem. Also, these fluctuations seemed to be due to a stronger self-esteem reactivity to perceived social devaluation for those high in narcissistic rivalry. Very few studies have looked at how state contingency differences among actors relate to social reactions of their interaction partners. In a field study on youth baseball coaches, Smith and colleagues (2009) identified specific situation-behavior contingencies that were significantly related to children's attitudes towards these coaches. The best liked coaches were characterized by an overall stronger supportive behavior but also a stronger contingency between winning and support ("if they win, then support"), while the least liked coaches were characterized by a strong contingency between losing and punitive behavior ("if they lose, then punish").

To date, most personality research on individual differences in state contingencies has not systematically disentangled the various specific kinds of interpersonal contingencies that together produce varying reactions across individuals. As described above, this includes differences in how interaction partners' behavior is perceived and experienced (differences in behavior $\rightarrow$ perception/affect contingencies), differences in how interpersonal perceptions and experiences drive one's own behavior (differences in perception/affect $\rightarrow$ behavior contingencies), and differences in how individuals react affectively to their interpersonal perceptions (differences in perception $\rightarrow$ affect contingencies). These different classes of interaction state associations and individual differences therein are investigated in a number of studies following interpersonal theory and often in the context of personality pathology (see Roche \& Cain, this volume, for a detailed summary of these findings). For example, in a 20-day event-contingent recording study on 38 patients with Borderline Personality Disorder (BPD) and 31 control participants, Sadikaj, Moskowitz, Russell, Zuroff, and Paris (2013) found that BPD participants reacted more strongly with quarrelsome behavior to perceiving cold-quarrelsome behavior in their interaction partners (behavioral reactivity to perceptions). 
This link could, moreover, be explained via negative affect: BPD participants more strongly reacted with negative affect to perceiving cold-quarrelsome behavior in their interaction partners (affective reactivity to perceptions), and negative affect was generally linked to one's own quarrelsome behavior (behavioral reactivity to negative affect). Using similar designs, it has been reported that social anxiety disorder is linked to a stronger embarrassment reaction following perceived cold behavior in interaction partners which then fosters own submissive behavior (Sadikaj, Moskowitz, Russell, \& Zuroff, 2016). Also, those high in pathological narcissism were found to particularly show quarrelsome behavior when perceiving the interaction partner as dominant. This was mediated via an increased negative affect reactivity to perceived dominance and an increased reactivity with quarrelsome behavior to negative affect (Wright et al., 2016).

The summarized studies and findings on interaction state contingencies are promising and move the field towards a more dynamic understanding of individual differences in social interactions that is more in line with existing conceptual approaches. They should, however, be interpreted with caution, and much more research is needed before robust conclusions can be drawn. There is still a lack of larger-scale systematic research on the basic psychometric properties of individual differences in dynamic states (see Wendt et al., 2019, for a recent example) and of more specific interaction state contingencies in particular. How many and what kind of these contingencies are reliable (consistent and stable)? How much do they correlate, that is, what contingencies refer to the same individual process differences and what are unique? Or in other words: What is the overarching structure of individual difference in interaction state contingencies? Also, with regard to associations with established trait measures, most findings pertain to specific, relatively small samples with few effects being directly replicated yet.

\section{Similarity and other relational effects: Individual differences in reactivities to specific interaction partners}


Although a substantial share of variance in interpersonal experiences and behaviors that make up social interaction processes is usually not explained by actor/perceiver or partner/target variances, not much is known about the relational predictors of this substantial "rest". Of course, a large portion of the variance that is found to be independent of main effects of interaction partners is random noise (Ingraham, \& Wright, 1986), but there is strong evidence for reliable and stable relationship variance as well (Back, Schmukle, \& Egloff, 2019; Kenny, 1994). Relationship effects (the unique experience or behavior towards a specific interaction partner) directly follow from individual differences in the interpersonal ifthen contingencies previously described. If an actor expresses more dominant behavior, and this is similarly linked to intimidation for all perceivers then this would only be reflected in target effects for this individual (i.e., being perceived as more intimidating). Similarly, if an actor expresses more sociable behavior and this is similarly linked to liking for all perceivers, this would only be reflected in being seen as more likeable in general, that is, a strong target effect. If, however, perceivers differ with regard to these contingencies (i.e. partner dominance $\rightarrow$ intimidation; partner sociability $\rightarrow$ liking), then relationship effects emerge (also see above and Back, Baumert et al., 2011). That is, relational effects will often be driven by some sort of the perceptional, affective, and behavioral reactivities just described.

Empirical research on determinants of such relational effects very often solely focuses on similarity effects and relates the similarity of abstract trait measures of two individuals to their relationship effects (e.g., investigate to what extent similarity in trait extraversion scores relate to unique liking/attraction). Similarity effects are simply a special case of these relational effects, where the same individual characteristic that predicts the strength to which a given behavior is expressed also predicts the strength to which this behavior as expressed by the interaction partner is linked to a given perception and evaluation, respectively. In other words, in case a trait (e.g., extraversion) predicts the "if" with regard to one's own behavior (i.e., extraverts act more sociable) as well as the "if-then" contingency with regard to the 
interaction partners behavior (i.e., extraverts like sociable partners more), a similarity effect emerges (i.e., extraverts like extraverts).

When it comes to romantic relationships, similarity effects in personality are often a default expectation both in lay conceptions and research. Empirically, however, they are often absent or small and inconsistent across studies (Dyrenforth, Kashy, Donnellan, \& Lucas, 2010; Luo \& Klohnen, 2005; Zentner, 2007). Importantly, it remains mostly unexamined which interaction processes underlie relational effects (or lack thereof). To understand similarity effects, more insights into the proximate variables by which romantic partners interact, choose each other, and develop a more or less satisfying relationship are needed. Before potential romantic partner meet, and thus without information on their mutual interactions, it seems to be very hard to predict romantic desire at all (Joel, Eastwick, \& Finkel, 2017). This casts some doubt on matchmaking approaches that focus on noninteractional information only. The groundbreaking work by Gottman and Levenson (1992), for example, indicates that the way romantic couples interact during conflict is crucial, specifically, the ratio of positive versus negative interactions during conflict episodes. While a couple of actor and partner main effects on the probability of more or less conflict interaction behavior and outcomes have been reported (e.g., Vater \& Schröder-Abé, 2015), the unique magic or toxic mix of partner characteristics is less clear.

The key question for research on relational effects in romantic relationships would be: What are the unique relations of partner characteristics that influence a uniquely positive or negative experience of a behavior during conflict, specifically expressed by this partner? Perhaps relations regarding the same personality characteristics (i.e., similarity) are not the most relevant in this context. Scant research has investigated other, more complex partner characteristic relations across trait dimensions. For example, Swann and colleagues (2003) found evidence for lower intimacy in romantic couples if verbally inhibited men matched up with verbally disinhibited women, and that this tendency was pronounced in highly critical 
women - a pattern they coined the "precarious couple effect". Further, in a study on personality, communication, and depressive symptoms across the transition to parenthood, Marshall, Simpson, and Rholes (2015) indicated that the combination of high actor neuroticism and low partner agreeableness had negative effects on the actor's well-being, particularly if prepartum dysfunctional problem-solving communication and aggression existed in the relationship.

In the context of peer relations, evidence for similarity effects regarding broad personality traits is again mixed, with some evidence for effects of similarity in extraversion, openness, and agreeableness on friendship selection (Selfhout et al., 2010). There is tentative evidence that similarity effects among peers are somewhat more pronounced for those personality characteristics that go along with unique preferences for behaviors, appearances, and environments that define social and societal subgroups. This is in line with social identity approaches (Abrams \& Hogg, 2004; Tajfel \& Turner, 1979), and has been found for values and attitudes, subcultural scenes, clothing, and music preferences (Back, Schmukle, \& Egloff, 2011; Newcomb, 1961; Selfhout, Branje, Ter Bogt, \& Meeus, 2009). Regarding these more group-based characteristics, the level one expresses the characteristics oneself might be more closely linked to the strength to which these characteristics are uniquely experienced as compared to characteristics that are less prominent in defining social in- and outgroups. Again, these processes underlying similarity effects are seldom examined. In one study that investigated unique perceptions at zero acquaintance, the effects of similarity in subcultural scene and clothing preferences on unique liking were mediated by a stronger fit between the targets' objective physical cues (related to fashionable and outlandish appearance) and the perceivers' preferences (Back, Schmukle, \& Egloff, 2011). In another longitudinal study (van Zalk, Nestler, Geukes, Hutteman, \& Back, in press), we found that similarity in extraversion predicted friendship selection via a more positive social interaction quality. Being with a 
more/less extraverted friend, in turn, predicted longitudinal changes in extraversion via mimicry of sociable behavior.

Again, it has to be kept in mind that similarity effects do not tell the whole story - and in many cases not even the most relevant one. Relational effects are more complex, often different for different poles of a personality dimension and often pertain to relations across different personality dimensions. There is very little available research directly tackling these complexities. In a study on dyadic interactions, Cuperman and Ickes (2009) found evidence for a similarity effect regarding extraversion: Interaction partners acted more friendly and self-disclosing and provided more positive reports about the interaction when both participants were introverted or both were extraverted. For agreeableness, in contrast, the interplay of actor and partner characteristics did not follow a similarity pattern. Instead, interaction behaviors and reports were particularly negative when two disagreeable participants met, while they were more positive when at least one of the participants was agreeable. Similar findings were revealed in a field study on peer-view similarity and friendship formation (van Zalk \& Denissen, 2015). In the study by Leikas and colleagues (2012), a number of specific interactions between actors personality and partners behaviors were found: High conscientiousness individuals were seen as more interested and likeable, and less awkward then low conscientious individuals when interacting with quarrelsome partners. Agreeable individuals nodded more when interacting with dominant partners. They also behaved less demanding (asked fewer questions) and felt better as compared to less agreeable individuals when interacting with submissive partners.

In general, future research should focus more on investigating relations of individual differences across different trait aspects (those relations that make sense from the generic conceptual perspective outlined above) and more directly investigate proximate processes that underlie unique experiences and behaviors towards specific interaction partners. It is also important to note that none of the previously reported actor-partner-interactions have been 
directly replicated. Collective efforts are needed to set up large scale high-powered registered replications before robust conclusions about similarity and other complex relational effects can be drawn.

Relational effects might also be explained in terms of stabilized relational if-then contingencies. That is, the more people have built up a relational disposition about another person, the more this person is stored in memory coupled with a host of typical thoughts, feelings, and behaviors one tends to experience and show when with this person. In a given actual interaction situation, the recognition of this person (or of someone similar to this person) might function as an "if" and directly triggers interaction state "thens". The activation of relational "if"s might also go along with different portions of one's self-concept being activated and different self-regulatory foci, thus implying unique state expressions and potentially also unique reactivities when with a given person. Such relation-specific contingencies have, for example, been described for significant others (Andersen, \& Thorpe, 2009). When with one's best friend, someone might almost automatically be in a better mood, feel more secure (relational-specific state levels), as well as show a greater readiness to perceive humor and to react with cheerfulness to perceived humor (relational-specific state contingencies). Such complex relation-specific interaction state dynamics await systematic empirical investigations across personality and relationship domains.

\section{Limitations, Perspectives, and Implications:}

\section{Understanding and Assessing Personality Traits as Dynamic Social Interaction Systems}

The described state of research on personality and social interaction processes refers to a large set of different research traditions, each with their unique conceptual and empirical approaches. It is my impression that several of these research traditions are currently experiencing a dynamic development themselves. Also, there is an increasing acknowledgment of similarities and fruitful complements across these traditions. My hope is that this development goes on and comes along with even more ambitious formalized 
conceptual models and empirical applications that match the richness and complexities of these models. Such a development will have non-trivial implications for how we define and assess interpersonal personality traits.

Although I have only given a selective overview on personality-oriented social interaction research, I have hopefully shown that this research has already provided an impressive amount of rich conceptual ideas and empirical insights regarding specific social interaction components and processes as well as their key role for understanding the structure, development, and consequences of personality. In the following, I will first describe two main limitations I feel the field needs to tackle: a circular way in how personality traits are dealt with and an insular way of investigating selected social interaction processes. Second, I will briefly hint at two further conceptual approaches that are currently up and coming in personality science and other fields - individual network and dynamic system approaches -, both of which directly address the outlined limitations and can themselves profit from a more detailed consideration of research on social interaction processes.

\section{Limitations: Fuzzy trait conceptualizations, insular and selective process analyses}

A first main limitation of current research on social interaction processes and personality (and of personality research in general, for that matter) regards the fuzzy way in which personality traits and their conceptual relation to social interaction processes are defined. This is not a new problem, but it becomes more and more apparent as personality research includes more fine-grained state process analyses. On the one hand, following a process-perspective it is argued that individual differences in social interaction processes define a trait (e.g., the trait extraversion is defined by individual differences in the propensity to engage in expressive behaviors and in the strength of the contingency between social cues and positive affect). On the other hand (and regularly within the same research), more in line with a classic latent trait perspective, this trait (assessed mostly by a self-report questionnaire) is dealt with as a predictor of these processes (e.g., predicting expressive behavior by the trait 
extraversion; trait extraversion as a moderator of the link between social cues and positive affect - or in other words prediction of social cue-affect contingency by trait extraversion). Conceptually, this is circular logic. Traits cannot at the same time be predictors of the processes that are used to define them in the first place: (a) "Traits cannot serve as explanations for those behaviors they summarize " (Baumert et al., 2017, p. 512), and (b) traits cannot serve as explanations for those state-state contingencies they summarize (also see the difference between the descriptive and explanatory part in Whole Trait Theory; Fleeson, this volume).

A second main limitation regards the insular and selective way in which current research on personality and social interaction processes is done. The previous interaction process investigations I have summarized are spread across different interpersonal, personality, emotion, clinical, and developmental research literatures with specific foci on selected process domains and a lack of cross-talk (see Hopwood, 2018 for the case of personality and clinical research). Current research also mostly focuses on one targeted interaction process at a time and does not sufficiently consider the joint contributions and dependencies of various systematically connected social interaction processes. Furthermore, most research analyzes social interaction processes in one particular context, at one particular point in time, and only considers linear associations among state variables, despite wide agreement that social interaction phenomena are dynamically evolving over time by means of complex linear and nonlinear processes.

To summarize, the science of personality and social interactions needs to (a) derive a clearer definition of personality traits as circumscribed between-person differences in withinperson social interaction processes and (b) better cover the dynamically evolving nature of social interaction processes. In tackling both of these limitations, the field might make use of two emerging perspectives in psychology: individual network and dynamic systems approaches. 


\section{Perspective 1: Integration with individual network approaches}

According to the classic latent trait perspective on personality, traits (e.g., extraversion, agentic narcissism) are not-directly observable but existing separate entities, hidden generators that work as causal factors and determine the range of states that are observable/assessable in the moment (e.g., affiliation motivation, sociable behavior, positive affect; perceiving admiration, pride, self-assured behavior). These latent traits are thought to be the sole reason for why the different indicators correlate. Also, personality differences are thought to develop due to environmental and/or genetic influences on the latent traits (which is then automatically reflected in all state indicators). Finally, measures that are thought to capture approximations of the latent trait scores are used to predict social outcomes (e.g., status, relationship satisfaction). This classic perspective is questionable both conceptually and empirically (see Mottus \& Allerhand, 2018, for a review). Conceptually, this perspective is contradicted by a range of process-approaches to personality such as the ones summarized in this chapter, indicating that the different indicators that are subsumed under the umbrella of a trait label are systematically and causally connected to each other independent of a hidden third variable (the latent trait). Perceiving admiration, for example, might foster the experience of pride which then might trigger more self-assured behavior. Individual differences in the tendency to perceive admiration will, therefore, translate into differences in the experience of pride and, thus, also into differences in self-assured behavior, which is one reason for why individual differences in all three indicators of narcissism are correlated. Empirically, even when only referring to standard self-report questionnaires, the structure of traits is represented by a fine differentiations of distinguishable personality facets and nuances per trait domain that show heritability, cross-rater agreement, and predictive validity independent of the shared "trait" variance (Mõttus, 2016; Mõttus, Kandler, Bleidorn, Riemann, \& McCrae, 2017). 
One of the alternative perspectives that does not refer to latent variables is the individual network perspective (Borsboom et al., 2011; Costantini, this volume; Cramer et al., 2012; Schmittmann et al., 2013). Following this perspective, traits are represented as between-person differences in within-person networks of personality elements with each element being depicted as a node and associations among characteristics being depicted as edges between the nodes. Importantly, elements of a network covary on a between-person level not because there is an underlying latent variable that causes all of these elements but because the elements themselves are related to each other for logical, causal, or homeostatic reasons. Applying this perspective to the field of personality and social interactions, the relevant elements (nodes) are social interaction states and the nodes refer to interaction state contingencies. A socially relevant trait such as agentic narcissism would be represented by stable differences between individuals in their network of narcissism-relevant states (e.g., perceiving admiration, pride, self-assured behavior). These differences pertain to (a) the level of interaction state expression (i.e., node strength; e.g., how much an individual shows selfassured behavior on average) and (b) the strength of interaction state contingencies (i.e., sign and strength of the edge; e.g., how strongly perceiving admiration links to the experience of pride within an individual). In addition, individuals can differ with regard to (c) more holistic network properties such as network centrality (i.e., what state elements are connected more strongly with other elements, being most effective in triggering and most susceptible to changes in the overall network) and network density (also known as small-worldness; i.e., how closely connected the nodes of a network are, being related to the ease with which changes spread across the whole network).

The individual network perspective represents an elegant, empirically based way of representing the clustering of social interaction states. This has seldom been done as most applications use standard self-report questionnaire items instead of properly assessed social interaction states as basic elements of the networks. The network perspective is, however, 
mostly silent with respect to the concrete processes and functional logic of the represented personality system. It does not spell out what state elements are to be included or how state elements are expected to relate to each other and form what kind of process chains and cycles within the network. That is, to allow for a valid representation of personality variables, the network approach needs to be combined with the rich variety of existing conceptual insights on relevant personality processes (see Denissen, Wood, \& Penke, 2012; Geukes et al., 2017). In the case of socially anchored traits, an integration with the research on social interaction processes summarized in this chapter seems fruitful.

For a complete understanding of individual differences in social interaction processes the networks also need to include external elements that reside outside of the individual. Specifically, and in accordance with the dynamics captured in the PERSOC model (Back, Baumert et al., 2011) and Contemporary Integrative Interpersonal Theory (Dawood et al., 2018; Pincus et al., in press), one has to include the perceptions, affective responses, and behaviors of social interaction partners as well. For example, self-assured behavior might lead others to view someone as a natural leader, which triggers social approval behaviors by others (e.g., attention, nodding) which then is perceived by the individual as a cue of admiration leading to the experience of pride and further strengthening self-assured behavior. Individual network representations can, in addition, also account for stabilizing forces outside of the state network. This includes individual differences in biological factors that influence the propensity with which certain interaction behaviors and social experiences are expressed. It also includes individual differences in self-concept memory storage that influence the propensity with which individuals evaluate themselves and their social goals in certain ways. Thus, a social interaction state network representation of social traits does by no means imply that there do not exist important biological and memory-stored determinants. These factors, however, very likely do not work via their influence on an overarching latent disposition and 
do not influence all state elements similarly but will have specific influences on some of the state network elements and/or some of the links between them.

A final nontrivial aspect that needs to be spelled out but is seldomly realized in individual network approaches is the question of how exactly an individual network reaches an equilibrium that defines an individual's personality over the course of time. The network of connected agentic narcissism-relevant state elements mentioned above can well explain how individuals differ from each other and stay different from each other. Someone who starts to behave more self-assured than others, for whatever reason, might increasingly do so via the positive and reinforcing connections to others' leadership perceptions and approval reactions, the perception of admiration, and experience of pride. Importantly, however, networks that only include positive linear associations among network elements are psychologically implausible because the elements of the network cannot grow endlessly. The agentic narcissistic network would explode. There are limits to the degree to which people can express self-assuredness and experience pride, for example. Thus, natural boundaries of interaction states need to be represented by nonlinear (e.g., logistic) associations among network elements (also see Blum, Rauthmann, Göllner, Lischetzke, \& Schmitt, 2018, for a similar reasoning outside of the context of individual networks). Another key ingredient that likely contributes to stabilized individual networks are negative feedback loops. Behaving self-assured can, for example, lead to the exhaustion of the experience of pride that triggered self-assuredness. Also, certain elements of the network can have both reinforcing and alleviating downstream consequences. Self-assured behavior, for example, might not only be perceived as an indication of leadership qualities (with the described reinforcing effects on self-assuredness) but also as being arrogant. This in turn might trigger social disapproval behaviors in others (e.g., frowning, head shaking). These social reactions might then be perceived as cues to disrespect by the individual, leading to anger and combative behavior representing antagonistic narcissistic dynamics that counteract the reinforcing agentic 
dynamics (e.g., Back, 2018). Finally, there might be external elements in which people differ that positively influence the strength of network links of two mutually alleviating network parts. Individual differences in the strive for status might, for example, increase the ease with which someone reacts with perceived admiration and pride to social approval cues as well as the ease with which someone reacts with perceived disrespect and anger to social disapproval cues (e.g., Grapsas, Brummelmann, Back, \& Denissen, 2020). Within and across social contexts this might lead to within-person fluctuations between self-stabilizing agentic and antagonistic narcissistic state expressions in those with a high strive for status. While both narcissistic modes should be uncorrelated or even negatively correlated within persons (it is difficult to be proud and angry, self-assured and aggressive at the same time), they should be positively correlated on a between-person level (those who more often engage in self-assured behaviors and have a stronger reactivity with pride to perceived admiration also tend to engage more often in aggressive behaviors and react more strongly with anger to perceived disrespect). Figure 5 shows an illustrative example for such an expanded individual network representation of narcissism as compared to a classic latent trait perspective.

- Fig. 5 -

\section{Perspective 2: Integration with dynamic system approaches}

More complete and dynamic network representations of personality and social interaction processes have yet to be fleshed out and better formalized for all sorts of social personality domains. To this aim, another conceptual tradition might be helpful that is currently gaining traction in mainstream psychology: dynamic systems approaches (e.g., Butner et al., 2015; Gallagher \& Appenzeller, 1999; Lewis, 2000; Thelen, \& Smith, 1994; van Geert, \& Fischer, 2009). Dynamic system approaches in psychology explicitly focus on development, changes in behavioral and experiential states over time, and the deeper formal logic behind these state variations. Like individual network representations of personality, dynamic system approaches consider personality traits as individual differences in individual 
systems that consist of a large number of elements (in our case social interaction states).

These elements are thought to be connected to each other and continuously interact with each other in such a nonlinear and self-organized way (i.e., without the need of an external controlling component, such as a latent trait) that stable behavioral and experiential patterns emerge in which individuals differ and that are typically understood as reflecting parts of their personality. Of particular appeal for a better understanding of personality and social interactions is the application of dynamic system modeling, the attempt to derive formalized mathematical models (mostly systems of differential equations) that explicitly model variations in interaction states over time and include non-linear dynamics. These models then aim at accurately predicting how an individual system will behave in the future - and how individuals differ therein.

A number of dynamic system approaches focusing on the closely related fields of personality dynamics (Cervone, 2005; Fajkowska, 2015; Jeronimus, 2019; Nowak, Vallacher, \& Zochowski, 2005; Pervin, 2001; Read et al., 2010; Richardson, Dale, \& Marsh, 2014; Sosnowska, Kuppens, De Fruyt, \& Hofmans, 2019; Vallacher, Michaels, \& Nowak, this volume), affective dynamics (Hollenstein et al., 2013; Kuppens, Oravecz, \& Tuerlinckx, 2010; Kuppens, \& Verduyn, 2017), and social interaction dynamics (Hollenstein \& Lewis, 2006; Gottman, Murray, Swanson, Tyson, \& Swanson, 2003; Pennings et al., 2014) have been introduced in recent years. Some of these approaches already provide mathematically formalized generic models of how personality systems stabilize and change and that show clear links to the social interaction dynamics outlined in this chapter. Nowak and colleagues (2005), for example, present models of how stability in individual differences emerges based on state synchronization during social interaction and higher-order self-concept organization.

Most current applications in personality psychology that can be summarized under the broad umbrella of dynamic system approaches, however, do not provide fully fledged-out formalized models but focus on deriving resulting system-like parameters such as variability 
(the range or amplitude of state fluctuations), inertia (the degree with which a state carries over from one moment to the next), and attractor force (the swiftness with which state deviations from one's average state are pulled back to this average) from intensive longitudinal within-person or within-dyad data (e.g., Sosnowska et al., 2019). These current efforts to describe personality via dynamic system parameters are, however, short on explaining how individual and dyadic differences in these parameters develop and what they exactly reflect. Partly as a consequence of this, it is currently also unclear how much different of these dynamic indices relate to each other (and how much they should) and whether they provide incremental information above and beyond state averages (e.g., Dejonckheere et al., 2019). As explained in detail above, intra-individual (as well as intra-dyadic) variability parameters are, strictly speaking, not psychological entities themselves but epiphenomena reflecting the strength and/or stability of specific interaction state contingencies. That is, dynamic system approaches need to be better linked with conceptual and empirical analyses on the concrete interaction processes that produce the system parameters that characterize different individuals (and dyads). Also, in line with the original logic of dynamic systems theory and modeling, increased efforts are needed to come up with mathematically formalized models that implement these conceptual ideas and are able to adequately describe observable between-person differences in within-person social interaction processes. Given that (a) research on social interaction processes is spread across diverse literatures and these processes need to be considered in their dependencies and joint contributions, and (b) few personality psychologists are trained in formal mathematical modeling, this will necessarily be an interdisciplinary endeavor. Based on such generic models, then, concrete empirical investigations and illustrations are needed that apply and directly test the utility of formal models based on real-life empirical data - using some of the trait and relationship domains as initial examples. 


\section{Implications: A dynamic social-interaction conceptualization and assessment of personality}

A dynamic social interaction conceptualization of personality that integrates insights and concepts from dynamic system and individual network approaches with the rich diversity of research on personality and social interactions comes along with a number of nontrivial challenges. First of all, it forces researchers to better define the content and boundaries of what is regarded as a trait. Theoretically, traits are simply regions of an overarching complete personality network/system. Depending on how broad or narrow the boundaries are drawn, the same variable can be part of a given trait system or considered as a determinant, correlate, or outcome of this system. There will not be one correct way of drawing these boundaries, and different strategies might be warranted depending on the theoretical focus and the research question at hand. Nevertheless, consensual definitions will be necessary to allow for effective scientific communication. Defining traits as parts of a dynamic social interaction system also directly relates to a different and more fine-grained understanding of (a) personality structure (overlap of trait domains in the kind of between-person differences in social interaction processes they refer to), (b) personality development (lasting changes in the levels and contingencies of social interaction states and their configuration, triggered by environmental and/or biological events that affect one or more elements of the system which then cause more or less lasting changes in other elements), and (c) personality consequences (triggered by specific elements in the personality state system that themselves are influenced by other elements of this system; see Geukes, \& Back, 2017).

Besides these conceptual challenges, a dynamic social interaction perspective on personality also has fundamental implications for the assessment of interpersonal personality traits. If we take the idea that individual differences in interaction state dynamics represent social traits seriously, and have defined for each trait what sort of state process differences a trait label refers to, we need to measure it accordingly. Importantly, traditional trait measures 
do not assess conceptual entities that are separate of what is measured with individual differences in interaction state processes but represent less direct proxy measures of (some of) these state process differences. Of course, optimally, one would be able to directly and continuously assess all sorts of interaction states and their contingencies that are relevant for a given trait and social context. This seems to be a Herculean task given that we do not only have to incorporate repeated self-reported experiences (perceptions, affect, cognitions) but also repeated behavioral state indicators as well as experiences and behaviors of social interaction partners and further objective characteristics of the social environment. But there are techniques already developed and increasingly used on all these levels (Bolger, \& Laurenceau, 2013; Geukes et al., 2019; Harari, Gosling, Müller, \& Stachl, this volume; Hofman, De Clercq, Kuppens, Verbeke, \& Widiger, 2019; Mehl \& Conner, 2012; Wright, \& Hopwood, 2016; Wrzus \& Mehl, 2015) - so I regard this as far less utopian than it might sound initially.

Realistically, however, few empirical investigations will be able to directly assess all of these relevant state aspects continuously. Thus, in the absence of a complete coverage of continuous social interaction processes, we might still need to additionally rely on traditional proxy measures (e.g., self-report questionnaires, acquaintance reports, implicit motive tests, batteries of behavioral and/or physiological tests in the laboratory) to assess some of the relevant individual differences that are not yet covered by more direct state assessments. Which individual differences in state processes (e.g., the average level of a behavior, a specific contingency between an environmental cue and an affective response) or external elements in the state system (e.g., self-concept memory storage; a biological reaction norm) a given proxy measure is thought to reflect needs to be carefully defined, however. Further important challenges regard the exact timing (i.e., number and frequency) of state assessments for different sorts of states as well as the standardization of analytical ways to derive empirical values from longitudinal state system data that characterize individuals and 
differences between individuals (e.g., aggregates as well as detailed portfolios of state levels and contingencies, dynamic parameters for specific states, overarching network/system configuration parameters).

\section{Conclusions}

The way we interact with others - how we approach a stranger, talk to our friends, fight with our neighbors, discuss with our partners, chat with our colleagues, negotiate with our roommates, play with our children - tells us a lot about ourselves, and at the same time it shapes who we are. Differences in these interactions are the core of what we describe as personality trait differences, and the long-term consequences of personality are mediated by these interactions. The scientific analyses of social interactions is a key issue in many research fields, and a number of recent conceptual and empirical developments have worked towards a better understanding of how personality is defined, expressed, develops, and exerts its influence by means of social interaction processes. Future research will have to engage in an even more systematic investigation of individual and dyadic differences in defined interaction process chains and towards formalized models that describe and predict the emergence and development of personality traits and social relationships by dynamic systems of social interaction processes. 


\section{Footnote}

${ }^{1}$ Contingencies can, in principle, be calculated between any two interaction state variables of one or two individuals. Following the PERSOC framework (Back, Baumert et al., 2011), I will exclusively focus on contingencies that potentially capture causal effects (e.g., between a behavior of Person A and a perception of Person B or between a perception of Person A and an affect of Person A). I will not consider contingencies that relate two variables that cannot be directly related causally for logical reasons (e.g., between a perception of Person A and a perception of Person B). 


\section{References}

Abele, A. E., \& Wojciszke, B. (2014). Communal and agentic content in social cognition. Advances in Experimental Social Psychology, 50, 195-255.

Abrams, D., \& Hogg, M. A. (2004). Metatheory: Lessons from Social Identity Research. Personality and Social Psychology Review, 8, 98-106.

Ames, D. R., \& Bianchi, E. C. (2008). The agreeableness asymmetry in first impressions: Perceivers' impulse to (mis)judge agreeableness and how it is moderated by power. Personality and Social Psychology Bulletin, 34, 1719-1736.

Anderson, N. H. (1968). Likeableness ratings of 5555 personality-trait words. Journal of Personality and Social Psychology, 9, 272-279.

American Psychiatric Association. (2013). Diagnostic and statistical manual of mental disorders (5th ed.). Arlington, VA: American Psychiatric Publishing.

Asendorpf, J. B. (1988). Individual response profiles in the behavioral assessment of personality. European Journal of Personality, 2, 155-167.

Asendorpf, J. B. (in press). Personality as a situation: A target-centered perspective on social situations. In J. F. Rauthmann, R. A. Sherman, \& D. C. Funder (Eds.), The Oxford handbook of psychological situations. New York, NY: Oxford University Press.

Back, M. D. (2015). Editorial. Opening the process-black box: Mechanisms underlying the social consequences of personality. European Journal of Personality, 29, 91-96.

Back, M. D. (2018). The Narcissistic Admiration and Rivalry Concept. In A. D. Hermann, A. Brunell, \& J. Foster (Eds.), The Handbook of trait narcissism: Key advances, research methods, and controversies (pp. 57-67). New York, NY: Springer.

Back, M. D., Baumert, A., Denissen, J. J. A., Hartung, F.-M., Penke, L., Schmukle, S. C., Schönbrodt, F. D., Schröder-Abé, M., Vollmann, M., Wagner, J., \& Wrzus, C. (2011). PERSOC: A unified framework for understanding the dynamic interplay of personality and social relationships. European Journal of Personality, 25, 90-107. 
Back, M. D., \& Kenny, D. A. (2010). The Social Relations Model: How to understand dyadic processes. Social and Personality Psychology Compass 4, 855-870.

Back, M. D., Küfner, A. C. P., Dufner, M., Gerlach, T. M., Rauthmann, J. F., \& Denissen, J. J. A. (2013). Narcissistic admiration and rivalry: Disentangling the bright and dark sides of narcissism. Journal of Personality and Social Psychology, 105, 1013-1037.

Back, M. D., Küfner, A. C. P., \& Leckelt, M. (2018). Early impressions of grandiose narcissists: A dual-pathway perspective. In A. D. Hermann, A. Brunell, \& J. Foster (Eds.), The Handbook of trait narcissism: Key advances, research methods, and controversies (pp. 309-316). New York, NY: Springer.

Back, M., \& Nestler, S. (2017). Dual-process approaches to personality. In R. Deutsch, B. Gawronski, \& W. Hofmann (Eds), Reflective and impulsive determinants of human behavior (pp. 137-154). New York, NY: Routledge.

Back, M. D., \& Nestler, S., (2016). Accuracy of Judging Personality. In J. A. Hall, M., Schmid Mast, \& T. V., West (Eds.). The social psychology of perceiving others accurately (pp. 98-124). Cambridge University Press.

Back, M. D., Schmukle, S. C. \& Egloff, B. (2009). Predicting actual behavior from the explicit and implicit self-concept of personality. Journal of Personality and Social Psychology, 97, 533-548.

Back, M. D., Schmukle, S. C. \& Egloff, B. (2011). A closer look at first sight: Social relations lens model analyses of personality and interpersonal attraction at zero acquaintance. European Journal of Personality, 25, 225-238.

Back, M., Schmukle, S. C., \& Egloff, B. (2019, January 15). From First Sight to Friendship: A Longitudinal Social Relations Analysis of Stability and Change in Interpersonal Attraction. $\underline{\text { https://doi.org/10.31234/osf.io/7qptu }}$

Back, M. D., \& Vazire, S. (2015). The social consequences of personality: Six suggestions for future research. European Journal of Personality, 29, 296-307. 
Bakan, D. (1966). The duality of human existence. Reading, PA: Addison-Wesley.

Bakeman, R., \& Gottman, J. M. (1997). Observing interaction: An introduction to sequential analysis (2nd ed.). New York: Cambridge University Press.

Baumeister, R. F., \& Leary, M. R. (1995). The need to belong: Desire for interpersonal attachments as a fundamental human motivation. Psychological Bulletin, 117, 497529.

Baumert, A., Schmitt, M., Perugini, M., Johnson, W., Blum, G., Borkenau, P., Costantini, G., ... Wrzus, C. (2017). Integrating personality structure, personality process, and personality development. European Journal of Personality, 31, 503-528.

Beck, A. T. (1979). Cognitive therapy of depression: Guilford Press.

Berry, D. S., \& Hansen, J. S. (2000). Personality, nonverbal behavior, and interaction quality in female dyads. Personality and Social Psychology Bulletin, 26, 278-292.

Blum, G. S., Rauthmann, J. F., Göllner, R., Lischetzke, T., and Schmitt, M. (2018). The Nonlinear Interaction of Person and Situation (NIPS) model: Theory and empirical evidence. European Journal of Personality, 32, 286-305.

Bolger N., \& Laurenceau J-P. (2013). Intensive longitudinal methods. An introduction to diary and experience sampling research. New York, N.Y.: Guilford Press.

Borkenau, P., \& Liebler, A. (1992). Trait inferences: Sources of validity at zero acquaintance. Journal of Personality and Social Psychology, 62, 645-657.

Borkenau, P., Mauer, N., Riemann, R., Spinath, F. M., \& Angleitner, A. (2004). Thin slices of behavior as cues of personality and intelligence. Journal of Personality and Social Psychology, 86, 599-614.

Borkenau, P., Riemann, R., Spinath, F. M. \& Angleitner, A. (2006). Genetic and environmental influences on person x situation profiles. Journal of Personality, 74, 1451-1479. 
Borsboom, D., Cramer, A. O. J., Schmittmann, V. D., Epskamp, S., \& Waldorp, L. J. (2011). The small world of psychopathology. PLOS ONE, 6, e27407.

Bowlby, J. (1988). A Secure Base. New York: Basic Books.

Breil, S. M., Geukes, K., Wilson, R. E., Nestler, S., Vazire, S., \& Back, M. D. (2019).

Zooming into real-life extraversion: How personality and situation shape sociability in social interactions. Collabra: Psychology, 5(1), 7. DOI:

http://doi.org/10.1525/collabra.170

Breil, S. M., Osterholz, S., Nestler, S., \& Back, M. D. (in press). Contributions of nonverbal cues to the accurate judgment of personality traits. In T.D. Letzring, \& J. S. Spain (Eds.). The Oxford handbook of accurate personality judgment. Oxford University Press.

Brunswik, E. (1956). Perception and the representative design of psychological experiments (2nd ed.). Berkeley: University of California Press.

Butner, J. E., Gagnon, K. T., Geuss, M. N., Lessard, D. A., \& Story, T. N. (2015). Utilizing topology to generate and test theories of change. Psychological Methods, 20, 1-25.

Carver, C. S., \& Scheier, M. E. (1981). Attention and self-regulation: A control theory approach to human behavior. NewYork,NY: Springer.

Cervone, D. (2005). Personality architecture: Within-person structures and processes. Annual Review Psychology, 56, 423-452.

Connelly, B. S., \& Ones, D. S. (2010). An other perspective on personality: Meta-analytic integration of observers' accuracy and predictive validity. Psychological Bulletin, 136, $1092-1122$.

Connolly, J. J., Kavanagh, E. J., \& Viswesvaran, C. (2007). The convergent validity between self and observer ratings of personality: A metaanalytic review. International Journal of Selection and Assessment, 15, 110-117. 
Costantini, G. (THIS VOLUME). Network analysis of dynamic personality data. In J. Rauthmann (Ed.), The handbook of personality dynamics and processes (pp. nn): Elsevier.

Cramer, A. O. J., van der Sluis, S., Noordhof, A., Wichers, M., Geschwind, N., Aggen, S. H., ... Borsboom, D. (2012). Dimensions of normal personality as networks in search of equilibrium: You can't like parties if you don’t like people. European Journal of Personality, 26, 414-431.

Creed, A. T., \& Funder, D. C. (1997). Social anxiety: From the inside and outside. Personality and Individual Differences, 25, 19-33.

Cronbach, L. J. (1955). Processes affecting scores on "understanding of others" and "assumed similarity.". Psychological Bulletin, 52(3), 177-193.

Cuperman, R., \& Ickes, W. (2009). Big Five predictors of behavior and perceptions in initial dyadic interactions: Personality similarity helps extraverts and introverts, but hurts “disagreeables”. Journal of Personality and Social Psychology, 97, 667-684.

Dawood, S., Dowgwillo, E.A., Wu, L.Z., \& Pincus, A.L. (2018). Contemporary integrative interpersonal theory of personality. In V. Zeigler-Hill \& T.K. Shackelford. (Eds.), The SAGE Handbook of Personality and Individual Differences (pp. 171-202). New York: Guilford.

Dejonckheere, E., Mestdagh, M., Houben, M., Rutten, I., Sels, L., Kuppens, P., \& Tuerlinckx, F. (2019). Complex affect dynamics add limited information to the prediction of psychological well-being. Nature Human Behaviour, 3(5), 478-491.

Denissen, J. J. A., Wood, D., \& Penke, L. (2012). Passing to the functionalists instead of passing them by. European Journal of Personality, 26, 436-437.

Denissen, J. J. A., Wood, D., Penke, L., \& van Aken, M. A. G. (2013). Self-regulation underlies temperament and personality: An integrative developmental framework. Child Development Perspectives, 7, 255-260. 
Dufner, M., Arslan, R. C., Hagemeyer, D., Schönbrodt, F. D., \& Denissen J. J. A. (2015). Affective contingencies in the affiliative domain: Physiological assessment, associations with the affiliation motive, and prediction of behavior. Journal of Personality and Social Psychology. 109, 662-676.

Dufner, M., Leising, D., \& Gebauer, J. E. (2016). Which basic rules underlie social judgments? Agency follows a zero-sum principle and communion follows a non-zerosum principle. Personality \& Social Psychology Bulletin, 42, 677-687.

Dyrenforth, P. S., Kashy, D. A., Donnellan, M. B., \& Lucas, R. E. (2010). Predicting relationship and life satisfaction from personality in nationally representative samples from three countries: The relative importance of actor, partner, and similarity effects. Journal of Personality and Social Psychology, 99, 690-702.

Eaton, L. G., \& Funder, D. C. (2003). The creation and consequences of the social world: An interactional analysis of extraversion. European Journal of Personality, 17, 375-395.

Endler, N. S., \& Hunt, J. M. (1966). Sources of behavioral variance as measured by the S-R Inventory of Anxiousness. Psychological Bulletin, 65, 336-346.

Endler, N. S., \& Magnusson, D. (1976). Toward an interactional psychology of personality. Psychological Bulletin, 83(5), 956-974. DOI: https://doi. org/10.1037/00332909.83.5.956

Erikson, E. H. (1959). Identity and the Life Cycle. New York: International Universities Press. Fajkowska, M. (2015). The Complex-System Approach to Personality: Main theoretical assumptions. Journal of Research in Personality, 56, 15-32

Fleeson, W. (2001). Towards a structure- and process-integrated view of personality: Traits as density distributions of states. Journal of Personality and Social Psychology, 80, $1011-1027$. 
Fleeson, W. (2004). Moving personality beyond the person-situation debate: The challenge and the opportunity of within-person variability. Current Directions in Psychological Science, 13, 83-87.

Fleeson, W. (2007). Situation-based contingencies underlying trait-content manifestation in behavior. Journal of Personality, 75(4), 825-862.

Fleeson, W., \& Gallagher, M. P. (2009). The implications of Big Five standing for the distribution of trait manifestation in behavior: Fifteen experience-sampling studies and a meta-analysis. Journal of Personality and Social Psychology, 97, 1097-1114.

Fleeson, W., \& Jayawickreme, E. (2015). Whole trait theory. Journal of Research in Personality, 56(1), 82-92.

Fournier, M. A., Moskowitz, D. S., \& Zuroff, D. C. (2008). Integrating dispositions, signatures, and the interpersonal domain. Journal of Personality and Social Psychology, 94, 531-545.

Funder, D. C. (1999). Personality judgment: A realistic approach to person perception. San Diego, CA: Academic Press.

Funder, D. C., \& Colvin, C. R. (1991). Explorations in behavioral consistency: Properties of persons, situations, and behaviors. Journal of Personality and Social Psychology, 60, 773-794.

Funder, D. C., Furr, R. M., \& Colvin, C. R. (2000). The Riverside Behavioral Q-Sort: A tool for the description of social behavior. Journal of Personality, 68, 451-489.

Fraley, C. R. (2002). Attachment stability from infancy to adulthood: Meta-analysis and dynamic modeling of developmental mechanisms. Personality and Social Psychology Review, 6(2), 123-151.

Gallagher, R., \& Appenzeller, T. (1999). Beyond reductionism. Science, 284, 79.

Geukes, K., \& Back, M.D. (2017). Towards a process-based understanding of personality structure, development, consequences, and assessment: Systemizing personality 
processes into state domains and sequences. European Journal of Personality, 31, $543-545$.

Geukes, K., Breil, S. M., Hutteman, R., Nestler, S., Küfner, A.C.P., Back, M.D. (2019). Explaining the longitudinal interplay of personality and social relationships in the laboratory and in the field: The PILS and the CONNECT study. PlosOne, 14(1), $\mathrm{e} 0210424$.

Geukes, K., Nestler, S., Hutteman, R., Dufner, M., Küfner, A. C. P., Egloff, B., Denissen, J. J. A., \& Back, M. D. (2017). Puffed-up but shaky selves: State self-esteem level and variability in narcissists. Journal of Personality and Social Psychology, 112(5), 769786.

Geukes, K., Nestler, S., Hutteman, R., Küfner, A.C.P., \& Back, M.D. (2017). Trait personality and state variability: Predicting individual differences in within- and cross-context fluctuations in affect, self-evaluations, and behavior in everyday life. Journal of Research in Personality, 69, 124-138.

Geukes, K., van Zalk, M. H. W., \& Back, M. D. (2017). Analyzing Processes in Personality Development. In J. Specht (Ed.). Personality development across the lifespan (pp. 455-472). San Diego: Elsevier.

Geukes, K. van Zalk, M. H. W., \& Back, M. D. (2018). Understanding Personality Development: An Integrative State Process Model. International Journal of Behavioral Development, 42, 43-51.

Gosling, S. D., Gaddis, S., \& Vazire, S. (2008). First impressions based on the environments we create and inhabit. In N. Ambady, \& J. J. Skowronski (Eds.), First Impressions (pp. 334-356). New York: Guilford.

Gottman, J. M. \& Levenson, R. W. (1992). Marital processes predictive of later dissolution: Behavior, physiology, and health. Journal of Personality and Social Psychology, 63, 221-233. 
Gottman, J. M., Murray, J. D., Swanson, C. C., Tyson, R., \& Swanson, K. R. (2003). The mathematics of marriage: Dynamic nonlinear models. Cambridge, MA: MIT Press

Grapsas, E., Brummelman, E., Back, M. D., \& Denissen, J. J. A. (2020). The “why” and "how" of narcissism: A process model of narcissistic status pursuit. Perspectives on Psychological Science, 15, 150-172.

Hall, J. A., Gunnery, S. D., Letzring, T. D., Carney, D. R., \& Colvin, C. R. (2017). Accuracy of judging affect and accuracy of judging personality: How and when are they related? Journal of Personality, 85, 583-592. doi: 10.1111/jopy.12262.

Hampson, S. E., Goldberg, L. R., \& John, O. P. (1987). Category-breadth and socialdesirability values for 573 personality terms. European Journal of Personality, 1, 241258.

Harari, G., Gosling, S., Müller, S., \& Stachl, C. (THIS VOLUME). Digital media technologies in the assessment of personality dynamics. In J. F. Rauthmann (Ed.), The handbook of personality dynamics and process (pp. nn). San Diego: Elsevier.

Heckhausen, H. (1991). Motivation and action. New York, NY: Springer-Verlag.

Hennecke, M., Bleidorn, W., Denissen, J. J.A., \& Wood, D. (2014). A three-part framework for self-regulated personality development across adulthood. European Journal of Personality, 28, 289-299.

Hilbig, B. E., Glöckner, A., \& Zettler, I. (2014). Personality and pro-social behavior: Linking basic traits and social value orientations. Journal of Personality and Social Psychology, 107, 529-539.

Hirschmüller, S., Breil, S. M., Nestler, S., \& Back, M. D. (in press). Lens and dual lens models. In T. D. Letzring, \& J. S. Spain (Eds.). The Handbook of Accurate Personality Judgment: Theory and Empirical Findings. Oxford University Press.

Hirschmüller, S., Egloff, B., Nestler, S., Back, M. D. (2013). The dual lens model: A comprehensive framework for understanding self-other agreement of personality 
judgments at zero acquaintance. Journal of Personality and Social Psychology, 104, 335-353.

Hirschmüller, S., Egloff, B., Schmukle, S. C., Nestler, S. \& Back, M. D. (2015). Accurate Judgments of Neuroticism at Zero Acquaintance: A Question of Relevance. Journal of Personality, 83, 221-228.

Hofman, J., De Clercq, B., Kuppens, P., Verbeke, L., \& Widiger, T. A (2019). Testing the structure and process of personality using ambulatory assessment data: An overview of within-person and person-specific techniques. Psychological Assessment, 31, 432443.

Hogan, R. (1983). A socioanalytic theory of personality. In M. M. Page (Ed.), 1982 Nebraska symposium on motivation (pp. 55-89). Lincoln: University of Nebraska Press.

Hollenstein, T., \& Lewis, M. D. (2006). A state space analysis of emotion and flexibility in parent-child interactions. Emotion, 6, 656-662.

Hollenstein, T., Lichtwarck-Aschoff, A., \& Potworowski, G. (2013). A model of socioemotional flexibility at three time scales. Emotion Review, 5, 397-405.

Holtzman, N. S., Vazire, S., \& Mehl, M. R. (2010). Sounds like a narcissist: Behavioral manifestations of narcissism in everyday life. Journal of Research in Personality, 44, $478-484$.

Hopwood, C. J. (2018). Interpersonal dynamics in personality and personality disorders. European Journal of Personality, 32, 499-524.

Hopwood, C. J., Schade, N., Krueger, R. F., Wright, A. G. C., \& Markon, K. E. (2013). Connecting DSM-5 personality traits and pathological beliefs: Toward a unifying model. Journal of Psychopathology and Behavioral Assessment, 35, 162-172.

Ingraham, L. J., \& Wright, T. L. (1986). A cautionary note on the interpretation of relationship effects in the social relations model. Social Psychology Quarterly, 49, 9397. 
Jeronimus, B.F. (2019). Dynamic system perspectives on Anxiety and Depression. In: Kunnen, E.S., de Ruiter, N.M.P., Jeronimus, B.F., van der Gaag, M.A. (Ed.), Psychosocial Development in Adolescence: Insights from the Dynamic Systems Approach (pp. 100-126). Routledge Psychology.

Joel, S., Eastwick, P. W., \& Finkel, E. J. (2017). Is romantic desire predictable? Machine learning applied to initial romantic attraction. Psychological Science, 28, 1478-1489.

Karelaia, N., \& Hogarth, R. M. (2008). Determinants of linear judgment: A meta-analysis of lens model studies. Psychological Bulletin, 134, 404-426.

Kenny, D. A. (1994). Interpersonal perception: A social relations analysis. New York: Guilford Press.

Kenny, D. A., \& Malloy, T. E. (1988). Partner effects in social interaction. Journal of Nonverbal Behavior, 12, 34-57.

Kenny, D. A., Mohr, C. D., \& Levesque, M. J. (2001). A social relations variance partitioning of dyadic behavior. Psychological Bulletin, 127, 128-141.

Kiesler, D. J. (1983). The 1982 Interpersonal Circle: A taxonomy for complementarity in human transactions. Psychological Review, 90, 185-214.

Krueger, J. I. (2009). A componential model of situation effects, person effects, and situationby-person interaction effects on social behavior. Journal of Research in Personality, $43,127-136$.

Küfner, A. C. P., Nestler, S., \& Back M. D. (2013). The two pathways to being an (un)popular narcissist. Journal of Personality, 81, 184-195.

Kuppens, P., Oravecz, Z., \& Tuerlinckx, F. (2010). Feelings change: Accounting for individual differences in the temporal dynamics of affect. Journal of Personality and Social Psychology, 99, 1042-1060.

Kuppens, P., \& Verduyn, P. (2017). Emotion dynamics. Current Opinion in Psychology, 17, 22-26. 
Lakey, B. (2016). Understanding the $\mathrm{P} \times \mathrm{S}$ Aspect of Within-Person Variation: A Variance Partitioning Approach. Frontiers in Psychology, 7.

Lawless DesJardins, N. M., Srivastava, S., Küfner, A. C. P., \& Back, M. D. (2015). Who attains status? Similarities and differences across social contexts. Social Psychological and Personality Science, 6, 692-700.

Leary, M. R. \& Baumeister, R. F. (2000). The nature and function of self-esteem: Sociometer theory. Advances in Experimental Social Psychology, 32, 1-62.

Leary, M. R. \& Downs, D. L. (1995). Interpersonal functions of the self-esteem motive: The self-esteem system as a sociometer. In M. Kernis (Ed.), Efficacy, agency, and selfesteem (pp. 123-144). New York: Plenum.

Leckelt, M., Geukes, K., Küfner, A.C.P., Niemeyer, L.M., Huttemann, R., Osterholz, S., Egloff, B., Nestler, N., \& Back, M.D. (in press). A longitudinal field investigation of narcissism and popularity over time: How agentic and antagonistic aspects of narcissism shape the development of peer relationships. Personality and Social Psychology Bulletin.

Leckelt, M., Küfner, A. C. P., Nestler, S., \& Back, M. D. (2015). Behavioral processes underlying the decline of narcissists' popularity over time. Journal of Personality and Social Psychology, 109, 856-871.

Leikas, S., Lönnqvist, J.-E., \& Verkasalo, M. (2012). Persons, situations, and behaviors: Consistency and variability of different behaviors in four interpersonal situations. Journal of Personality and Social Psychology, 103, 1007-1022.

Leising, D., \& Bleidorn, W. (2011). Which are the basic meaning dimensions of observable interpersonal behavior? Personality and Individual Differences, 51, 986-990.

Levesque, M. J., \& Kenny, D. A. (1993). Accuracy of behavioral predictions at zero acquaintance: A social relations analysis. Journal of Personality and Social Psychology, 65, 1178-1187. 
Lewis, M. D. (2000). The promise of dynamic systems approaches for an integrated account of human development. Child Development, 71, 36-43.

Lucas, R. E., \& Baird, B. M. (2004). Extraversion and emotional reactivity. Journal of Personality and Social Psychology, 86, 473-485.

Lucas, R. E., Le, K., \& Dyrenforth, P. S. (2008). Explaining the extraversion/positive affect relation: Sociability cannot account for extravert's greater happiness. Journal of Personality, 76, 385-414.

Luo, S. \& Klohnen, E. C. (2005). Assortative mating and marital quality in newlyweds: A couple-centered approach. Journal of Personality and Social Psychology, 88, 304-326.

Malloy, T. E., \& Kenny, D. A. (1986). The Social Relations Model: An integrative methodology for personality research. Journal of Personality, 54, 199-225.

Marshall, E. M., Simpson, J. A., \& Rholes, W. S. (2015). Personality, communication, and depressive symptoms across the transition to parenthood: A dyadic longitudinal investigation. European Journal of Personality, 29, 216-234.

McClelland, D. C. (1987). Human motivation. New York, NY: Cambridge University Press.

Mehl, M. R., \& Conner, T. S. (Eds.) (2012). Handbook of research methods for studying daily life. New York, N.Y.: Guilford Press.

Meier, L. M., Orth, U., Denissen, J. J. A., \& Kühnel, A. (2011). Age differences in instability, contingency, and level of self-esteem across the life span. Journal of Research in Personality, 45, 604-612.

Mischel, W., \& Shoda, Y. (1995). A cognitive-affective system theory of personality: Reconceptualizing situations, dispositions, dynamics, and invariance in personality structure. Psychological Review, 102, 246-268.

Mischel, W. \& Shoda, Y. (1998). Reconciling processing dynamics and personality dispositions. Annual Review of Psychology, 49, 229-258. 
Mischel, W., \& Shoda, Y. (2008). Towards a unified theory of personality: Integrating dispositions and processing dynamics within the cognitive-affective processing system. In: John, O. P., Robins, R. W., \& Pervin, L. A. (Eds.), Handbook of personality psychology: Theory and research, 3rd ed., 208-241. New York: Guilford Press.

Morf, C. C. (2006). Personality reflected in a coherent idiosyncratic interplay of intra- and interpersonal self-regulatory processes. Journal of Personality, 74, 1527-1556.

Moskowitz, D. S., \& Zuroff, D. C. (2004). Flux, pulse, and spin: Dynamic additions to the personality lexicon. Journal of Personality and Social Psychology, 86, 880-893.

Mõttus, R. (2016). Towards more rigorous personality trait-outcome research. European Journal of Personality, 30, 292-303.

Mottus, R., \& Allerhand, M. (2018). Why do traits come together? The underlying trait and network approaches. In V. Zeigler-Hill, \& T. K. Shackelford (Eds.), SAGE Handbook of Personality and Individual Differences: The Science of Personality and Individual Differences [6] London: SAGE. DOI: 20.500.11820/385b5bbd-bf64-4726-9cda-

\section{$\underline{5685 \mathrm{e} 961 \mathrm{~b} 032}$}

Mõttus, R., Kandler, C., Bleidorn, W., Riemann, R., \& McCrae, R. R. (2017). Personality traits below facets: The consensual validity, longitudinal stability, heritability, and utility of personality nuances. Journal of Personality and Social Psychology, 112, $474-490$.

Mund, M. \& Neyer, F. J. (THIS VOLUME). Wild horses dressed like unicorns: Relationship effects on personality. In J. F. Rauthmann (Ed.), The handbook of personality dynamics and process (pp. nn). San Diego: Elsevier.

Nestler, S. \& Back, M.D. (2013). Applications and extensions of the lens model to understand interpersonal judgments at zero acquaintance. Current Directions in Psychological Science, 22, 374-379. 
Nestler, S., Egloff, B., Küfner, A. C. P., \& Back, M. D. (2012). An integrative lens model approach to bias and accuracy in human inferences: Hindsight effects and knowledge updating in personality judgments. Journal of Personality and Social Psychology, 103, $689-717$.

Newcomb, T. M. (1961). The acquaintance process. New York: Holt, Rinehart, and Winston.

Neyer, F. J., Mund, M., Zimmermann, J. \& Wrzus, C. (2014). Personality-relationship transactions revisited. Journal of Personality, 82, 539-550.

Nowak, A., Vallacher, R. R., \& Zochowski, M. (2005). The emergence of personality: Dynamic foundations of individual variation. Developmental Review, 25, 351-385

Pennebaker, J. W., \& King, L. A. (1999). Linguistic styles: Language use as an individual difference. Journal of Personality and Social Psychology, 77, 1296-1312.

Pennings, H. J., van Tartwijk, J., Wubbels, T., Claessens, L. C., van der Want, A. C., \& Brekelmans, M. (2014). Real-time teacher-student interactions: A dynamic systems approach. Teaching and Teacher Education, 37, 183-193.

Perugini, M., Hagemeyer, B. Wrzus, C. \& Back, M. D. (THIS VOLUME). Dual process models of personality. In J. F. Rauthmann (Ed.), The handbook of personality dynamics and process (pp. nn). San Diego: Elsevier.

Pervin, L. A. (2001). A dynamic systems approach to personality. European Psychologist, 6, $172-176$

Pilkonis, P. A. (1977). The behavioral consequences of shyness. Journal of Personality, 45, 596-611.

Pincus, A.L., Hopwood, C.J., \& Wright, A.G.C. (in press). The interpersonal situation: An integrative framework for the study of personality, psychopathology, and psychotherapy. In J.F. Rauthmann, D. Funder, \& R. Sherman (Eds.), Oxford Handbook of Psychological Situations. Oxford, UK: Oxford University Press. 
Pittman, T. S., \& Zeigler, K. R. (2007). Basic human needs. In A. W. Kruglanski \& E. T. Higgins (Eds.), Social psychology: Handbook of basic principles (2nd ed., pp. 473489). New York, NY, US: Guilford Press.

Rau, R., Carlson, E. N., Back, M. D., Barranti, M., Gebauer, J. E., Human, L., Leising, D., \& Nestler, S. (in press). What is the structure of perceiver effects? On the importance of global positivity and trait-specificity across personality domains and judgment contexts. Journal of Personality and Social Psychology.

Rau, R., Nestler, S., Geukes, K., Back, M. D., \& Dufner, M. (2019). Can other-derogation be beneficial? Seeing others as low in agency can lead to an agentic reputation in newly formed face-to-face groups. Journal of Personality and Social Psychology 117(1), 201-227.

Rau, R., Nestler, W., Dufner, M., \& Nestler, S. (in press). Seeing the best or worst in others: Introducing a measure of generalized other-perceptions. Assessment.

Rauthmann, J. F. (2016). Motivational factors in the perception of psychological situation characteristics. Social and Personality Psychology Compass, 10(2), 92-108.

Rauthmann, J. F., Sherman, R. A., \& Funder, D. C. (2015). Principles of situation research: Towards a better understanding of psychological situations. European Journal of Personality, 29, 363-381

Read, S. J., Monroe, B. M., Brownstein, A. L., Yang, Y., Chopra, G., \& Miller, L. C. (2010). A neural network model of the structure and dynamics of human personality. Psychological Review, 117, 61-92.

Reitz, A. K., Zimmermann, J., Hutteman, R., Specht, J., \& Neyer, F. J. (2014). How peers make a difference: The role of peer groups and peer relationships in personality development. European Journal of Personality, 28, 279-288.

Richardson, M. J., Dale, R., \& Marsh, K. L. (2014). Complex dynamical systems in social and personality psychology: Theory, modeling, and analysis. In H. T. Reis \& C. M. Judd 
(Eds.), Handbook of research methods in social and personality psychology (pp. 253282). New York, NY, US: Cambridge University Press.

Riggio, H. R., \& Riggio, R. E. (2002). Emotional expressiveness, extraversion, and neuroticisms: A meta-analysis. Journal of Nonverbal Behavior, 26, 195-218.

Roberts, B. W. (2009). Back to the future: Personality and assessment and personality development. Journal of Research in Personality, 43, 137-145.

Roberts, B. W., \& Jackson, J. J. (2008). Sociogenomic personality psychology. Journal of Personality, 76, 1523-1544.

Roberts, B. W., Wood, D., \& Smith, J. L. (2005). Evaluating five factor theory and social investment perspectives on personality trait development. Journal of Research in Personality, 39, 166-184.

Robinson, M. D. (2007). Personality, affective processing, and self-regulation: toward process-based views of extraversion, neuroticism, and agreeableness. Social and Personality Psychology Compass, 1, 223-235

Roche, M. J., \& Cain, N. M. (THIS VOLUME). Interpersonal theory and personality processes. In J. Rauthmann (Ed.), The handbook of personality dynamics and processes (pp. nn): Elsevier.

Russell, J.A. (1980). A circumplex model of affect. Journal of Personality and Social Psychology, 39, 1161-1178.

Rusting, C. L., \& Larsen, R. L. (1997). Extraversion, neuroticism, and the susceptibility to positive and negative affect: A test of two theoretical models. Personality and Individual Differences, 22, 607-612.

Sadikaj, G., Moskowitz, D. S., Russell, J. J., Zuroff, D. C., \& Paris, J. (2013). Quarrelsome behavior in borderline personality disorder: Influence of behavioral and affective reactivity to perceptions of others. Journal of Abnormal Psychology, 122, 195-207. 
Sadikaj, G., Moskowitz, D. S., Russell, J. J., \& Zuroff, D. C. (2015). Submissiveness in social anxiety disorder: the role of interpersonal perception and embarrassment. Journal of Social and Clinical Psychology, 34, 1-27.

Sadikaj, G., Moskowitz, D. S., \& Zuroff, D. C. (2017). Intrapersonal variability in interpersonal perception in romantic relationships: Biases and accuracy. Journal of Research in Personality, 69, 67-77.

Sadler, P., Ethier, N., \& Woody, E. (2011). Interpersonal complementarity. In L. M. Horowitz \& S. Strack (Eds.), Handbook of interpersonal psychology: Theory, research, assessment, and therapeutic interventions (pp. 123-142). Hoboken, NJ: John Wiley \& Sons.

Scherer, K. R. (1978). Personality inference from voice quality: The loud voice of extraversion. European Journal of Social Psychology, 8, 467-487.

Schmittmann, V. D., Cramer, A. O. J., Waldorp, L. J., Epskamp, S., Kievit, R. A., \& Borsboom, D. (2013). Deconstructing the construct: A network perspective on psychological phenomena. New Ideas in Psychology, 31, 43-53.

Selfhout, M.H.W., Branje, S., Ter Bogt, T., \& Meeus, W. (2009). The role of music preferences in the formation and stability of friendships. Journal of Adolescence, 32, 95-107.

Selfhout, M.H.W., Burk, W., Branje, S., Denissen, J. J. A., Van Aken, M. A. G., \& Meeus, W. (2010). Emerging late adolescent friendship networks and Big Five personality traits: A social network perspective. Journal of Personality, 78, 509-538.

Sherman, R. A., \& Pashler, H. (2019, May 24). Powerful Moderator Variables in Behavioral Science? Don’t Bet on Them (Version 3). https://doi.org/10.31234/osf.io/c65wm

Sherman, R. A., Rauthmann, J. F., Brown, N. A., Serfass, D. G., \& Jones, A. B. (2015). The independent effects of personality and situations on real-time expressions of behavior and emotion. Journal of Personality and Social Psychology, 109(5), 872-888. 
Shoda, Y., Mischel, W., \& Wright, J. C. (1994). Intraindividual stability in the organization and patterning of behavior: Incorporating psychological situations into the idiographic analysis of personality. Journal of Personality and Social Psychology, 67, 674-687.

Shrauger, J. S. \& Schoeneman, T. J. (1979). Symbolic interactionist view of self-concept: Through the looking glass darkly. Psychological Bulletin, 86, 549-573.

Smith, R. E., Shoda, Y., Cumming, S. P., \& Smoll, F. L. (2009). Behavioral signatures at the ballpark: Intraindividual consistency of adults' situation-behavior patterns and their interpersonal consequences. Journal of Research in Personality, 43, 187-195.

Snyder, M., \& Ickes, W. (1985). Personality and social behavior. In G. Lindzey, \& E. Aronson (Eds.), Handbook of social psychology (volume II, third edition). New York: Random House.

Sosnowska, J., Kuppens, P., De Fruyt, F., \& Hofmans, J. (2019). A dynamic systems approach to personality: The Personality Dynamics (PersDyn) model. Personality and Individual Differences, 144, 11-18.

Sperber, D., \& Wilson, D. (1986). Relevance: Communication and Cognition. Oxford: Blackwell.

Srivastava, S., Guglielmo, S., \& Beer, J. S. (2010). Perceiving others' personalities: Examining the dimensionality, assumed similarity to the self, and stability of perceiver effects. Journal of Personality and Social Psychology, 98(3), 520-534.

Stopfer, J. M., Egloff, B., Nestler, S., \& Back, M. D. (2014). Personality expression and impression formation in online social networks: An integrative approach to understanding the processes of accuracy, impression management, and meta-accuracy. European Journal of Personality, 28, 73-94.

Swann, W. B., Jr., \& Bosson, J. K. (2008). Identity negotiation: A theory of self and social interaction. In O. P. John, R. W. Robins \& L. A. Pervin (Eds.), Handbook of personality: theory and research (pp. 448-471). New York: Guilford. 
Swann, W. B., Rentfrow, P. J., \& Gosling, S. D. (2003). The precarious couple effect: Verbally inhibited men + critical, disinhibited women $=$ bad chemistry. Journal of Personality and Social Psychology, 85(6), 1095-1106.

Tajfel, H. \& Turner, J. C. (1979). An integrative theory of intergroup conflict. In W. Austin \& S. Worchel (Eds.), The social psychology of intergroup relations (pp. 33-48). Pacific Grove, CA: Brooks/Cole.

Tett, R. P., \& Burnett, D. D. (2003). A personality trait-based interactionist model of job performance. Journal of Applied Psychology, 88(3), 500-517.

Tett, R. P., \& Guterman, H. A. (2000). Situation trait relevance, trait expression, and crosssituational consistency: Testing a principle of trait activation. Journal of Research in Personality, 4(34), 397-423.

Thelen, E., \& Smith, L. B. (1994). A dynamic systems approach to the development of cognition and action. Cambridge, MA: MIT Press-Bradford Books.

Thielmann, I., Hilbig, B. E., \& Zettler, I. (2020). Seeing me, seeing you: Testing competing accounts of assumed similarity in personality judgments. Journal of Personality and Social Psychology, 118(1), 172-198. https://doi.org/10.1037/pspp0000222

Tiedens, L. Z., \& Jimenez, M. C. (2003). Assimilation for affiliation and contrast for control: complementary self-construals. Journal of Personality and Social Psychology, 85(6), 1049-1061.

Vallacher, R., Michaels, J. L., \& Nowak, A. (THIS VOLUME). Identifying the dynamics of individual variation in personality. In J. Rauthmann (Ed.), The handbook of personality dynamics and processes (pp. nn): Elsevier.

van Geert, P., \& Fischer, K. W. (2009). Dynamic systems and the quest for individual-based models of change and development. In J. P. Spencer, M. S. C. Thomas, \& J. L. McClelland (Eds.), Toward a unified theory of development: Connectionism and dynamic systems theory re-considered. Oxford: Oxford University Press. 
van Zalk, M., \& Denissen, J. J. A. (2015). Idiosyncratic versus social consensus approaches to personality: Self-view, perceived, and peer-view similarity. Journal of Personality and Social Psychology, 109, 121-141.

van Zalk, M. H. W., Nestler, S., Geukes, K., Hutteman, R., \& Back, M. D. (in press). The codevelopment of extraversion and friendships: Bonding and behavioral mechanisms in friendship networks. Journal of Personality and Social Psychology

Vater, A., \& Schröder-Abé, M. (2015). Explaining the link between personality and relationship satisfaction: Emotion regulation and interpersonal behaviour in conflict discussions. European Journal of Personality, 29, 201-215.

Vazire, S. (2010). Who knows what about a person? The self-other knowledge asymmetry (SOKA) model. Journal of Personality and Social Psychology, 98, 281-300.

Vazire, S., \& Sherman, R. A. (2017). Introduction to the special issue on within-person variability in personality. Journal of Research in Personality, 69, 1-3.

Wendt, L. P., Wright, A. G., Pilkonis, P. A., Woods, W. C., Denissen, J. J. A., Kühnel, A., \& Zimmermann, J. (2019, April 17). The Structure of Emotional Daily Dynamics. doi: $\underline{10.31234 / \text { osf.io/nyqst }}$

Wiggins, J. S. (1991). Agency and communion as conceptual coordinates for the understanding and measurement of interpersonal behavior. In W. M. Grove, \& D. Ciccetti (Eds.), Thinking clearly about psychology: Vol. 2. Personality and psychopathology (pp. 89-113). Minneapolis: University of Minnesota Press.

Wood, D., \& Denissen, J. J. A. (2015). A functional perspective on personality trait development. In N. R. Branscombe \& K. Reynolds (Eds.), Psychology of change: Life contexts, experiences, and identities (pp. 97-115). New York, NY: Psychology Press.

Wood, D., Harms, P., \& Vazire, S. (2010). Perceiver effects as projective tests: What your perceptions of others say about you. Journal of Personality and Social Psychology, 99(1), 174-190. 
Wright, A.G.C., \& Hopwood, C. J. (2016). Advancing the assessment of dynamic psychological processes. Assessment, 23, 399-403.

Wright, A.G.C., Stepp, S.D., Scott, L.N., Hallquist, M.N., Beeney, J.E., Lazarus, S., \& Pilkonis, P.A. (2016). The effect of pathological narcissism on interpersonal and affective processes in social interactions. Journal of Abnormal Psychology, 126, 898910.

Wrzus, C. (THIS VOLUME). Processes of personality development: An update of the TESSERA framework. In J. Rauthmann (Ed.), The handbook of personality dynamics and processes (pp. nn): Elsevier.

Wrzus, C., \& Mehl, M. (2015). Lab and/or field? Measuring personality processes and their social consequences. European Journal of Personality, 29, 250-271.

Wrzus, C., \& Roberts, B. W. (2017). Processes of personality development in adulthood: The TESSERA framework. Personality and Social Psychology Review, 21, 253-277.

Wurst, S. N., Gerlach, T. M., Dufner, M., Rauthmann, J. F., Grosz, M. P., Küfner, A. C. P., Denissen, J. J. A., \& Back, M. D. (2017). Narcissism and romantic relationships: The differential impact of narcissistic Admiration and Rivalry. Journal of Personality and Social Psychology, 112, 280-306.

Yik, M., Russel, J. A., \& Steiger, J. H. (2011). A 12-point circumplex structure of core affect. Emotion, 11, 705-731.

Zeigler-Hill, V., Holden, C. J., Enjaian, B., Southard, A. C., Besser, A., Li, H., \& Zhang, Q. (2015). Self-esteem instability and personality: The connections between feelings of self-worth and the Big Five dimensions of personality. Personality and Social Psychology Bulletin, 41, 183-198.

Zentner, M. R. (2005). Ideal mate personality concepts and compatibility in close relationships: A longitudinal analysis. Journal of Personality and Social Psychology, $89,242-256$. 


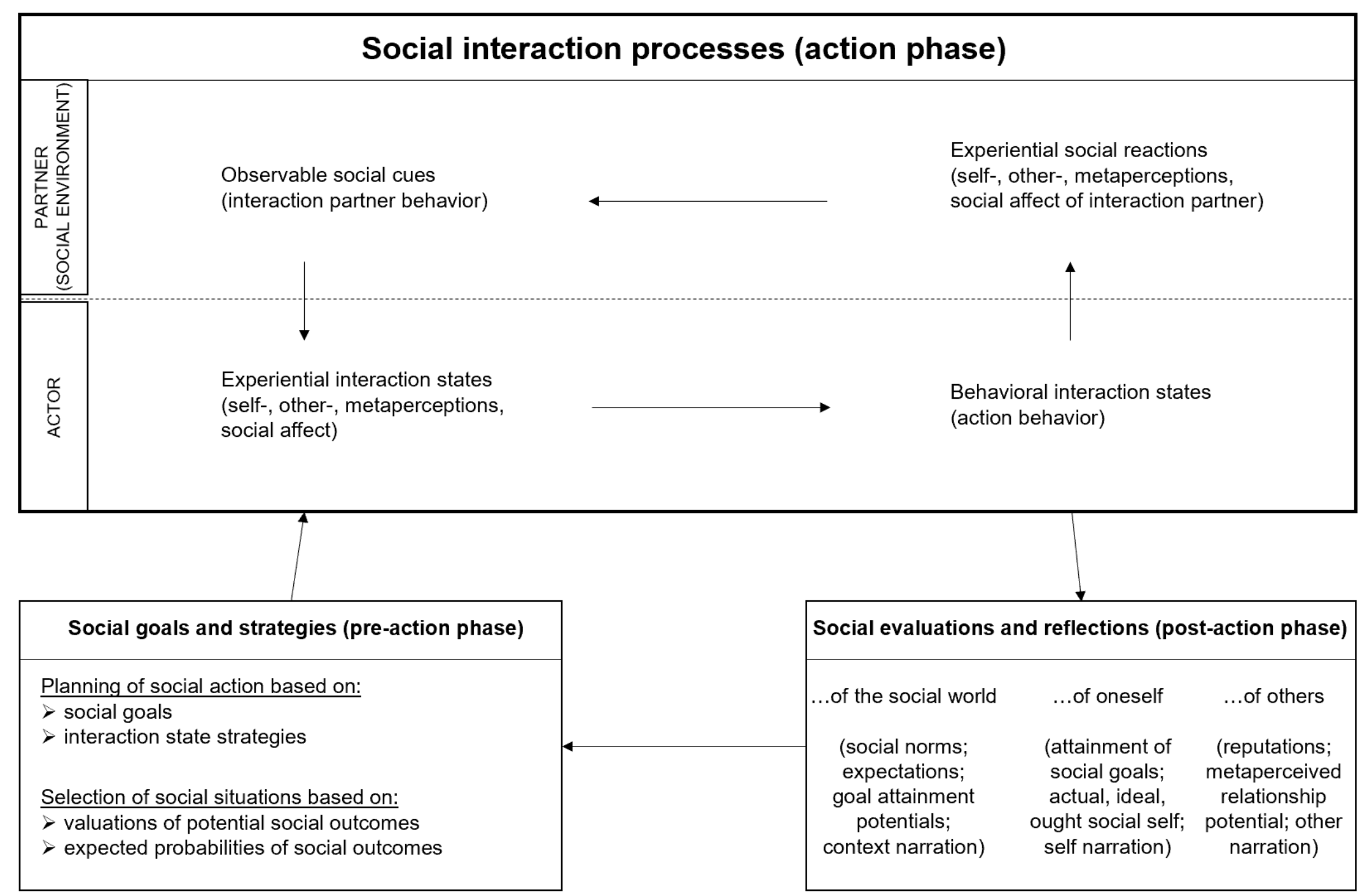

Figure 1. A generic state process model of personality (see Geukes et al., 2018) focusing on social interaction processes. 

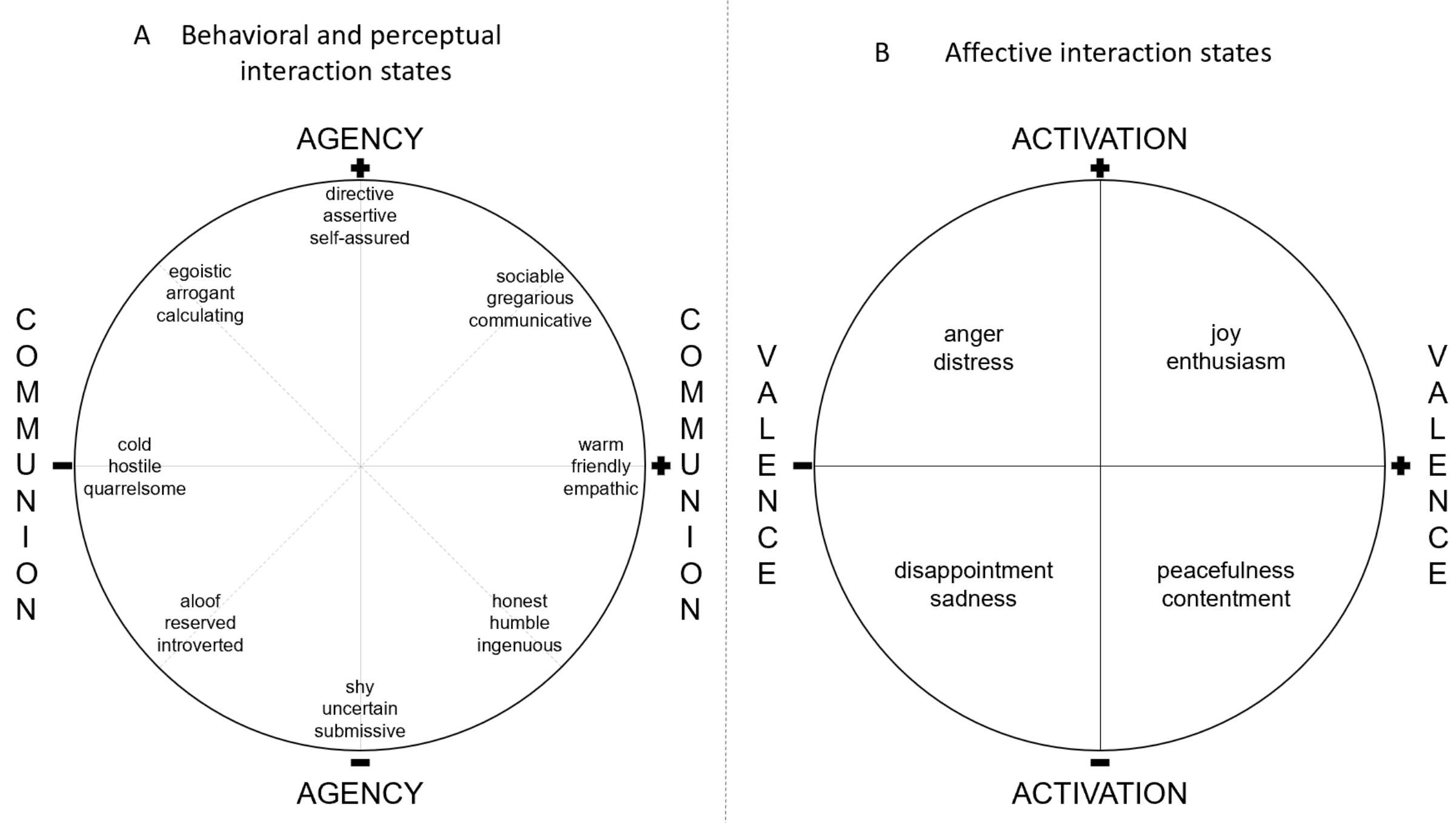

Figure 2. Circumplex representations of behavioral, perceptual (A) and affective (B) social interaction states. 


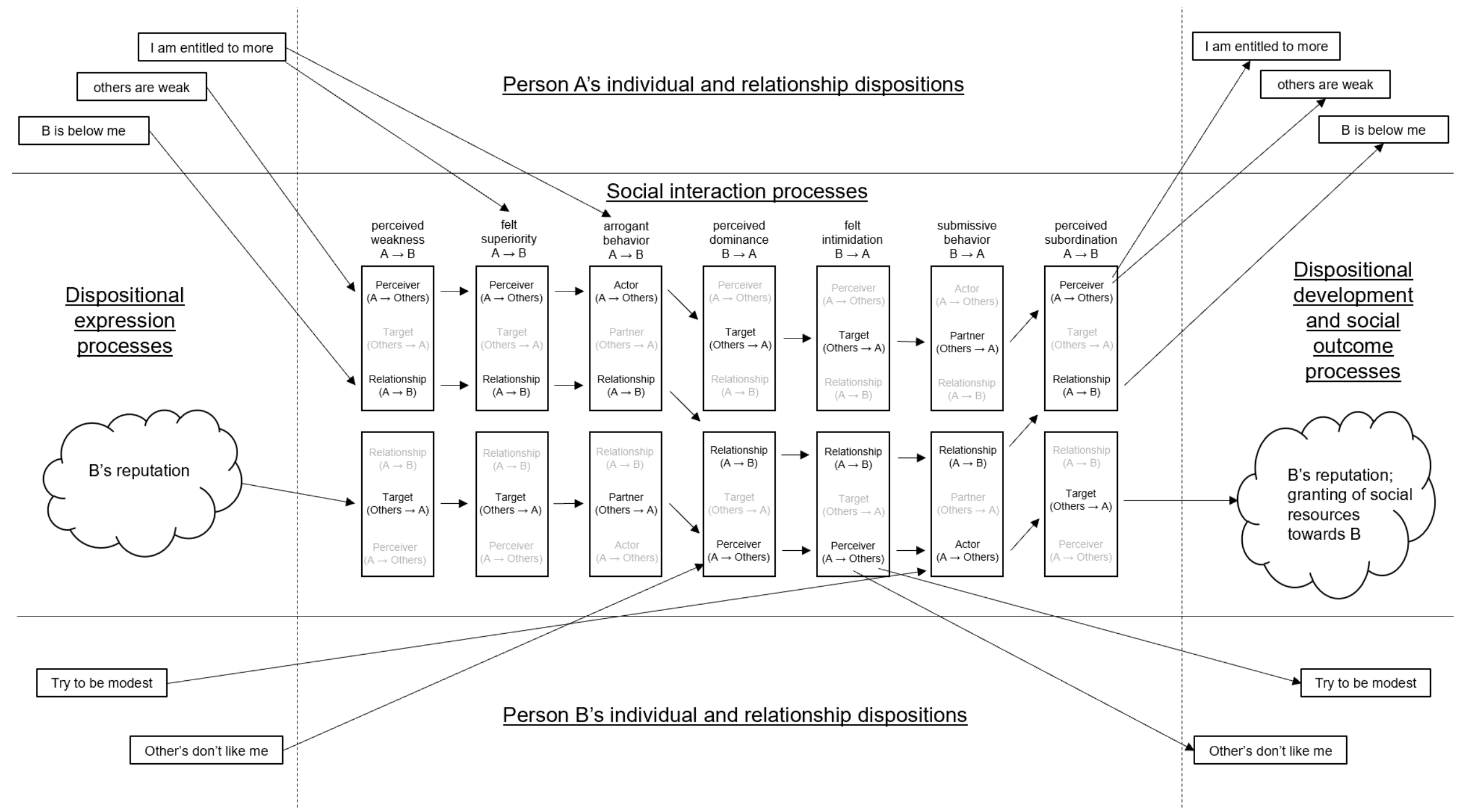

Figure 3. An exemplary illustration of dispositional expression, social interaction, dispositional development and social outcome processes according to the PERSOC framework. 


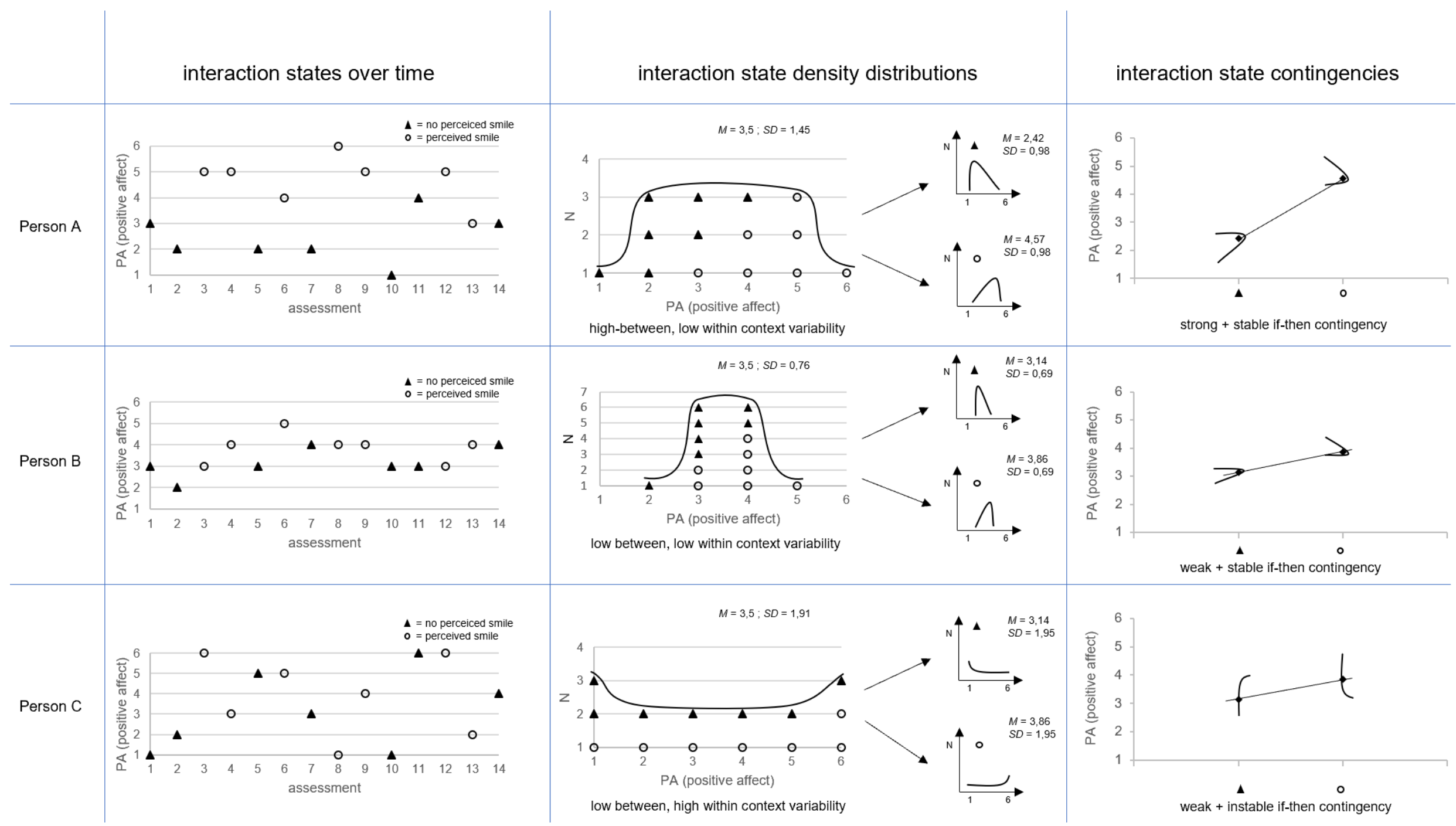

Figure 4. An illustration of the relation between within-person state variability within and across similar (psychological) situations and the strength and stability of within-person if-then contingencies. 


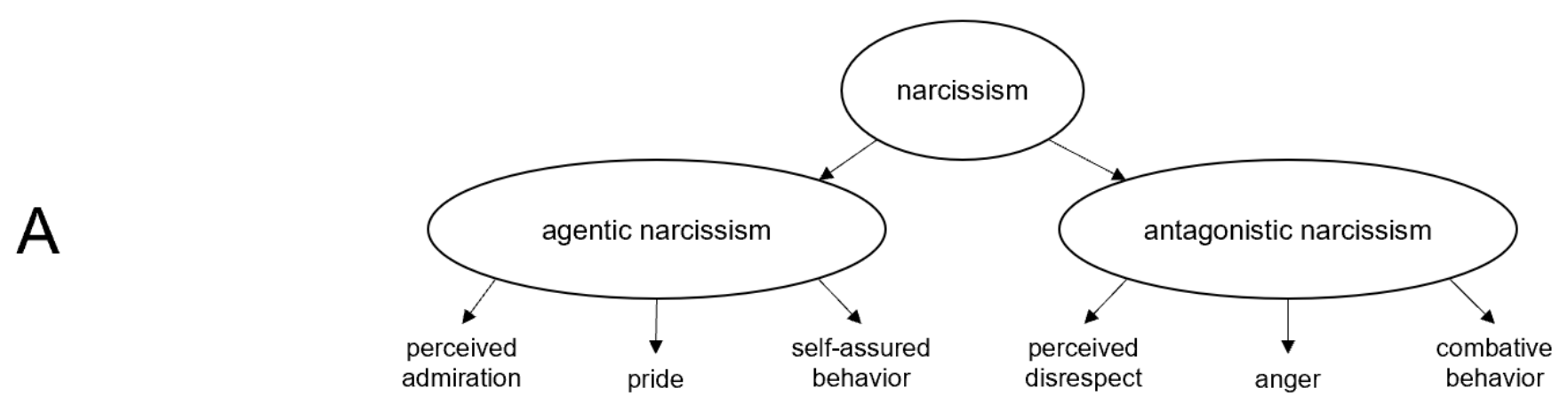

B

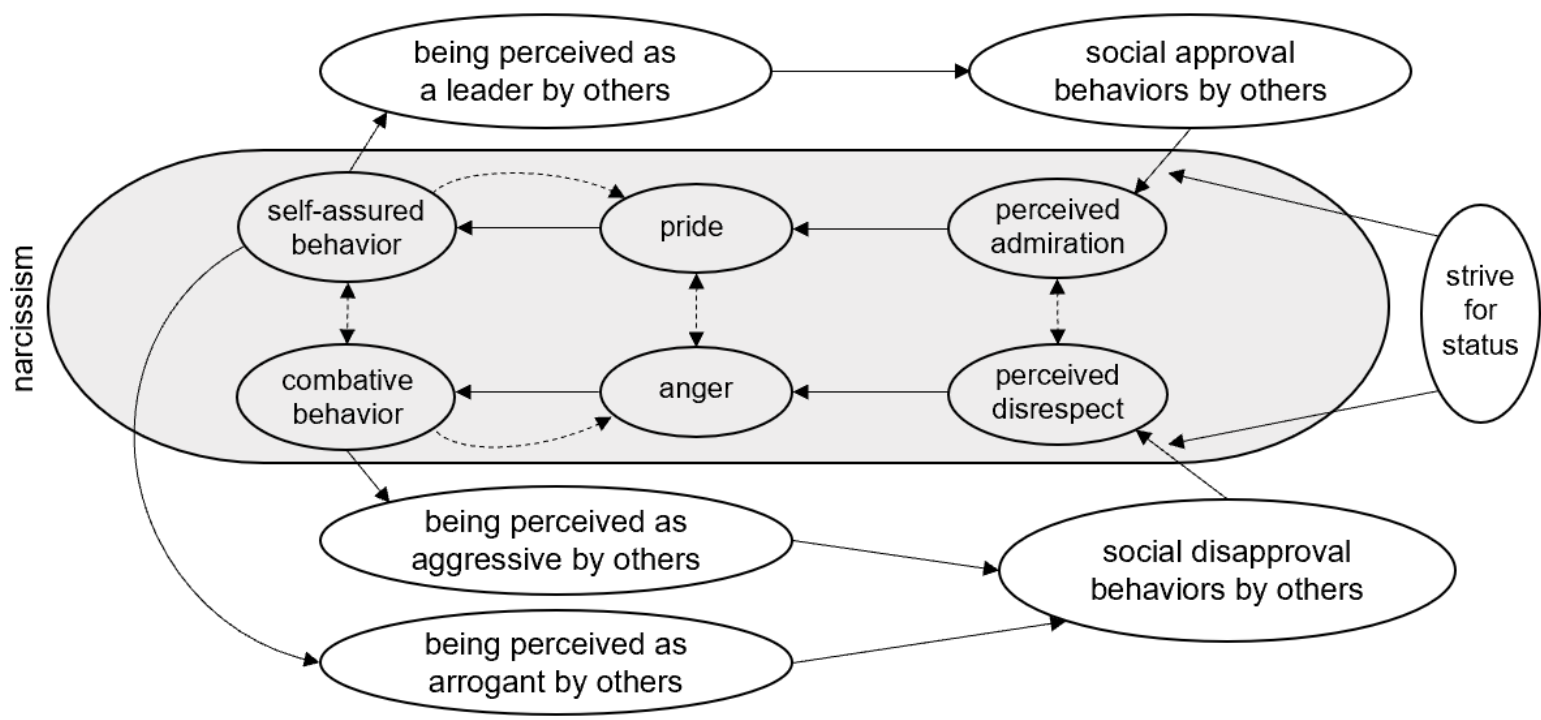

Figure 5. An illustrative conceptual representation of narcissism according to a classic latent trait model (A) and a dynamic social interaction process network model (B). 